\title{
Process Selection for the Fabrication of Cavitation Erosion- Resistant Bronze Coatings by Thermal and Kinetic Spraying in Maritime Applications
}

\author{
Michél Hauer ${ }^{1}\left(\right.$ C) Frank Gärtner ${ }^{2} \cdot$ Sebastian Krebs $^{2} \cdot$ Thomas Klassen $^{2}$ • \\ Makoto Watanabe $^{3} \cdot$ Seiji Kuroda $^{3} \cdot$ Werner Krömmer $^{4} \cdot$ Knuth-Michael Henkel $^{5}$
}

Submitted: 25 September 2020/in revised form: 11 February 2021/ Accepted: 23 March 2021/Published online: 25 May 2021

(C) The Author(s) 2021

\begin{abstract}
The present study compares prerequisites for cavitation-resistant bronzes production by different coating techniques, namely cold spraying, HVOF spraying, warm spraying and arc spraying. If optimized to maximum cavitation resistance, the deposited coatings can increase the service life of ship rudders significantly. Furthermore, these methods could enable repair processes for ship propellers. This study is meant to help selecting the right coating technology to achieve best cavitation protection for a given set of requirements. Using high-pressure warm spraying and cold spraying, properties similar to those of cast nickel aluminum bronze are achieved. Also, coatings produced by using HVOF and arc spraying have erosion rates that are only about four, respectively, three times higher as compared to cast nickel aluminum bronze, while by far outperforming bulk shipbuilding steel. Their properties should be sufficient for longer service life, i.e., less docking events for ship rudder repair. Hence, with respect to costs, HVOF and arc spraying could represent a good compromise to
\end{abstract}

Michél Hauer

michel.hauer@igp.fraunhofer.de

1 Fraunhofer Institute for Large Structures in Production Engineering IGP - Thermal Joining Engineering, Rostock, Germany

2 Helmut-Schmidt University / University of the Federal Armed Forces Hamburg - Department of Mechanical Engineering, Hamburg, Germany

3 National Institute for Materials Science NIMS - Research Center for Structural Materials, Tsukuba, Ibaraki, Japan

$4 \quad$ Linde plc - Packaged Gases Germany Retail \& Welding Applications / Thermal Spraying, Unterschleissheim, Germany

5 University of Rostock - Chair of Joining Technology, Rostock, Germany reach the specified coating properties needed in application, potentially even for propeller repair.

Keywords cavitation-resistant coatings · cold spray · HVOF - marine components - microstructure - warm spray · wire arc spray

\section{Introduction}

Cavitation phenomena occurring at the hull and in particular at the rudder reduce the efficiency and safety of fastmoving seagoing vessels. Dynamic pressure fluctuations caused by rudder movements during course changes or aft sea cannot be prevented even by optimizing hydrodynamic characteristics (Ref 1). Local pressure fluctuations are sufficiently large to trigger cavitation, i.e., the formation and implosion of vapor bubbles. In the long term, cyclic loading leads to material fatigue and local erosion from the surface (Ref 2), see Fig. 1. In practice, ships are docked every 5-7 years in order to repair the damage that has occurred in the rudder area by means of weld cladding and grinding work (Ref 3, 4).

As promising alternative, the use of thermal and kinetic spray techniques to fabricate cavitation erosion-resistant coatings is thoroughly explored. So far, individual optimization procedures for the different spray techniques have been reported in literature (Ref 5-7). However, up to now, a comprehensive comparison of optimized coatings obtained by different techniques is still missing. As a guideline for process selection, the present study describes procedures and individually optimized properties of aluminum bronze coatings as achieved by applying different spray techniques. Respective data are evaluated in comparison with those of bulk materials like shipbuilding steel and highly 


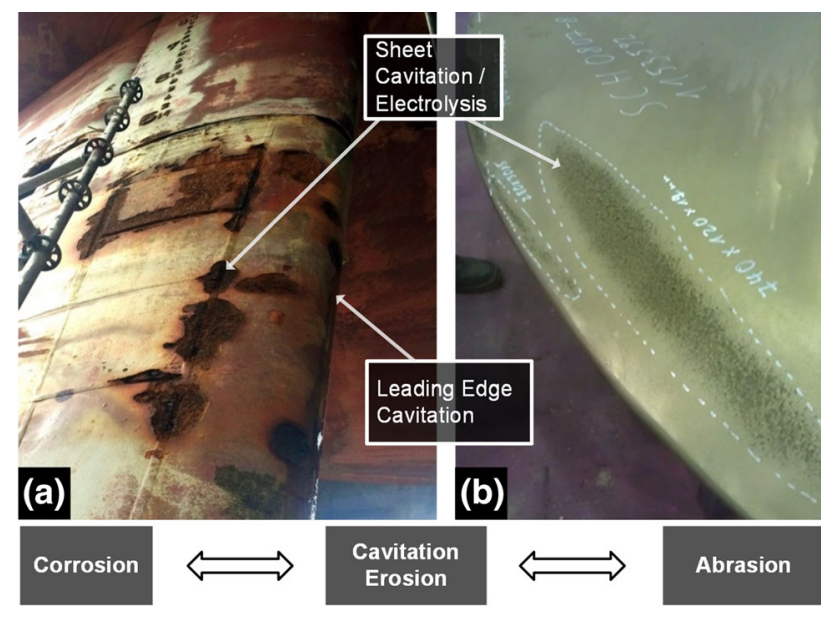

Fig. 1 Erosive damages (a) in the rudder area of a containership and (b) on the blade of a ship propeller

cavitation erosion-resistant nickel aluminum propeller bronze. For an easier assessment, this work refers to coatings on flat structures and a typical coating thickness in the range of $300-600 \mu \mathrm{m}$.

In comparison with weld cladding, thermal spraying or cold spraying has the advantage of avoiding surface melting of the respective part, and thus eliminating disadvantages by intermixing between the base and the deposit material. Therefore, there is no restriction in the choice of deposit material: brittle phases resulting from liquid phase mixing and solidification do not occur ( $\operatorname{Ref} 8,9)$. Comparing both technologies, cold spraying can offer the advantage over thermal spraying to avoid any oxidation by the impact in solid state (Ref 10,11). Thermal spraying processes such as arc and plasma spraying as well as flame and high-velocity oxy-fuel (HVOF) flame spraying are established for several decades in a wide range of applications from vehicle construction, aircraft construction to plant construction in order to apply corrosion- or wearresistant coatings (Ref $8,9,12,13$ ). The special emphasis on cold spraying is motivated by potentially allowing for high-end coating properties similar to the bulk material, even for processing of Al-bronzes as high-strength materials (Ref 10,11). However for both technologies, defects in the coatings such as oxides in thermal spraying or poorly bonded internal interfaces in cold spraying must be minimized to reach sufficiently good mechanical properties and thus also cavitation erosion resistance. Therefore, in the following a short overview of the spraying technologies used for the experimental tests as well as on individual measures for coating optimization will be given.

In cold spraying, particles are accelerated in an inert high-pressure gas jet as they pass through a converging/diverging nozzle (De-Laval) to impact the component surface at supersonic speed (Ref 14).
Figure 2 presents a schematic illustrating the principle of this coating method. In order to achieve higher gas velocities when passing through the smallest nozzle cross section, and thus higher particle velocities overall, the process gas is usually preheated to several hundred to maximum of about one thousand degrees Celsius, hence facilitating deformation of the particles at impact (Ref 10). The decisive factor for bonding is that the released heat under fast and severe plastic deformation locally softens the material at the interface and that this softening dominates over all hardening mechanisms, thus causing adiabatic shear instabilities (ASI) (Ref 15). For successful deposit formation, the powder particles must have velocities $\left(v_{\mathrm{p}}\right)$ on impact that are higher than the corresponding material-specific and temperature-dependent critical velocities $\left(v_{\text {crit }}\right)$. For the coating properties, it is decisive, in which ratio the particle velocity $\left(v_{\mathrm{p}}\right)$ exceeds the critical velocity $\left(v_{\text {crit }}\right)$, defining the coating quality parameter $\eta=$ $v_{\mathrm{p}} / v_{\text {crit }}$ (Ref 10,15). However, a possible disadvantage of the process is that it is not as widely distributed as other spraying technologies.

High-velocity oxy-fuel (HVOF) flame spraying is characterized by the fact that (i) molten particles are only briefly exposed to the surrounding atmosphere and thus oxidize only slightly, and that (ii) high impact velocities ensure dense coating structures (Ref 16,17). The process provides a good option for gaining very good coating properties, while at the same time being well established on the market. With respect to mechanical properties, however, possible influences by oxides have to be minimized. In HVOF spraying with gas as fuel, the oxygen-fuel ratio can be varied well into the sub-stoichiometric range (Ref $18,19)$. This reduces the flame temperature and minimizes the amount of free oxygen in the flame and jet, and thus also the oxidation of the sprayed material (Ref 12, 18, 19). Systems with gas cooling of the combustion chamber wall and powder injection into the combustion chamber allow a further reduction of the oxidation of the spray material, especially if nitrogen is used as cooling gas for shrouding the particle stream (Ref 20). As an example of such a system, Fig. 3 shows a schematic illustrating the principle of the HVOF spraying system Diamond Jet 2700 Hybrid from Oerlikon Metco.

Within this comparison, arc spraying is known as a simple and very cost-effective thermal spraying method (Ref 21, 22), just utilizing an arc between two spray wire tips to melt the feedstock material. With rather limited droplet acceleration, these technique thus represents the low-end of velocity regimes among the methods applied in this study. However, advantages concern the high productivity and simple infrastructure similar to arc welding processes as available on shipyards. One or more gas jets, usually compressed air, are used to atomize the molten 


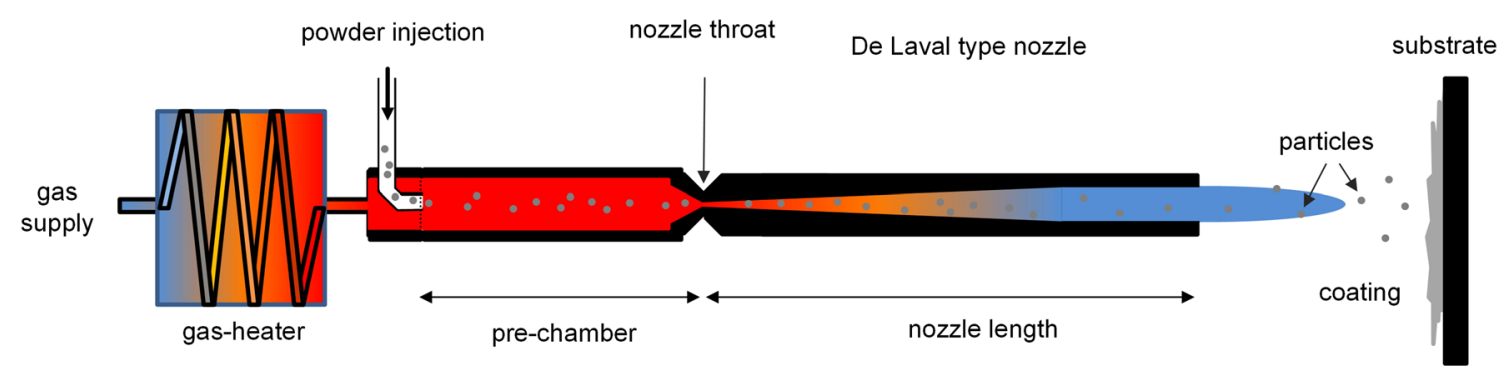

Fig. 2 Schematic drawing of the cold spraying principle. The gas temperature flow along the nozzle axis is represented by the colors red (hot) to blue (cold) (Ref 5)

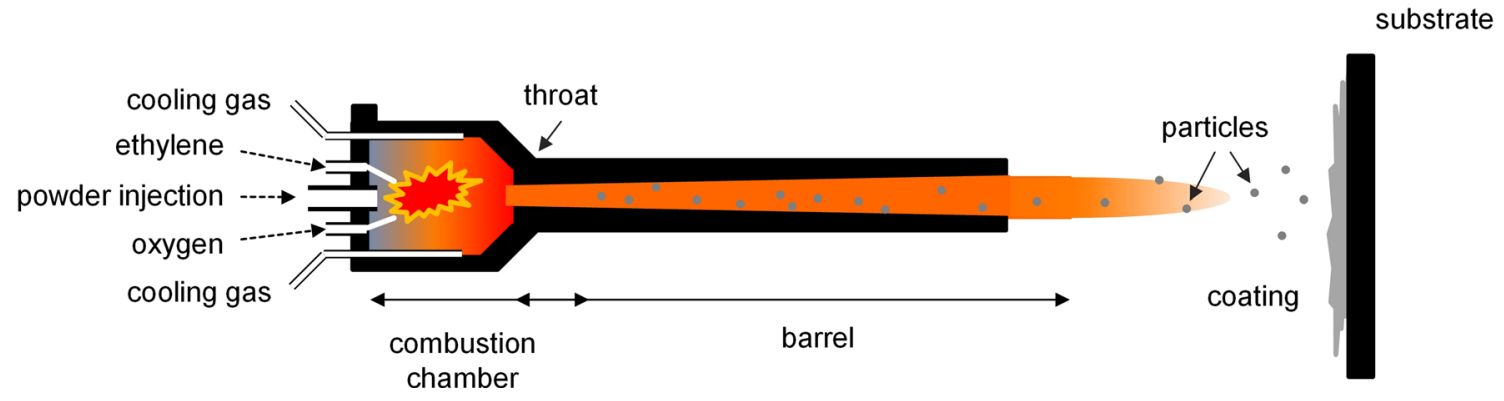

Fig. 3 Schematic diagram of the HVOF spraying system Diamond Jet 2700 Hybride from Oerlikon Metco (Ref 5)

metal and to propel it onto the prepared work piece surface (Ref 23). Arc spraying is characterized by well-known key factors (Ref 21,22) and is established for corrosion protection of large structures and for on-site repairs (Ref 24, 25). Therefore, it has also being considered for the restoration of eroded ship rudders and the near-contour spraying of propellers (Ref 21, 26, 27). The final coating quality is mainly influenced by arc voltage and current as well as gas flow, pressure and gas type (Ref 22, 28). Recent developments in arc spraying consider open torch concepts with free, directed flow toward the wire tips to ensure a less divergent particle jet and higher particle velocities of up to $360 \mathrm{~m} / \mathrm{s}$ (Ref 12, 29), a comparison to conventional setups being illustrated in Fig. 4.

Additionally, the type of atomizing gases can significantly improve the quality of arc sprayed coatings (Ref $22,27)$. As alternatives to compressed air, gases such as nitrogen or mixtures of nitrogen and hydrogen can provide a less reactive atmosphere. Particularly, additions of reducing hydrogen can significantly reduce the oxygen content of the coatings (Ref 22).

As second solid-state impact technique in addition to cold spraying, also warm spraying was evaluated within the frame of the technological comparison. This process was considered as promising alternative to overcome limitations of cold spraying with respect to the use of hard powders and needed rise of available process temperature regimes. As developed at the National Institute for Materials Science (NIMS) in Tsukuba/Japan, warm spraying is based on the HVOF technique by adding gas cooling at the end of the combustion chamber. The principle is schematically illustrated in Fig. 5. The project-related experiments were performed at NIMS.

As in HVOF spraying, by applying liquid fuels, oxygen and kerosene are mixed and subsequently ignited and burned in a combustion chamber (Ref 30$)$. The combustion initially results in high gas temperatures of up to $2700{ }^{\circ} \mathrm{C}$. Depending on oxygen pressure and combustion conditions, process gas pressures of typically up to $1 \mathrm{MPa}$ can be set under standard conditions. Under high-pressure conditions, process gas pressures of up to $4 \mathrm{MPa}$ can be achieved (Ref 31). In a mixing chamber downstream of the combustion chamber, but before the converging section, nitrogen is fed into the process as a coolant. Depending on the $\mathrm{N}_{2}$ flow rates of typically between 500 and $1000 \mathrm{l} / \mathrm{min}$, lower process gas temperatures can be achieved. Following the mixing chamber, the gas passes through the converging and diverging sector of a Laval nozzle. The feedstock powder is fed into the gas stream downstream nozzle throat and is accelerated and heated according to the local gas conditions. As compared to cold spraying, warm spraying ensures similar particle velocities but higher particle temperatures. The sprayed material usually remains in the solid state, thus minimizing oxidation while providing sufficient heating to the particles (Ref 5,30). Dealing with solid-state particle impacts, the bonding mechanisms in warm spraying are the same as for cold spraying. 

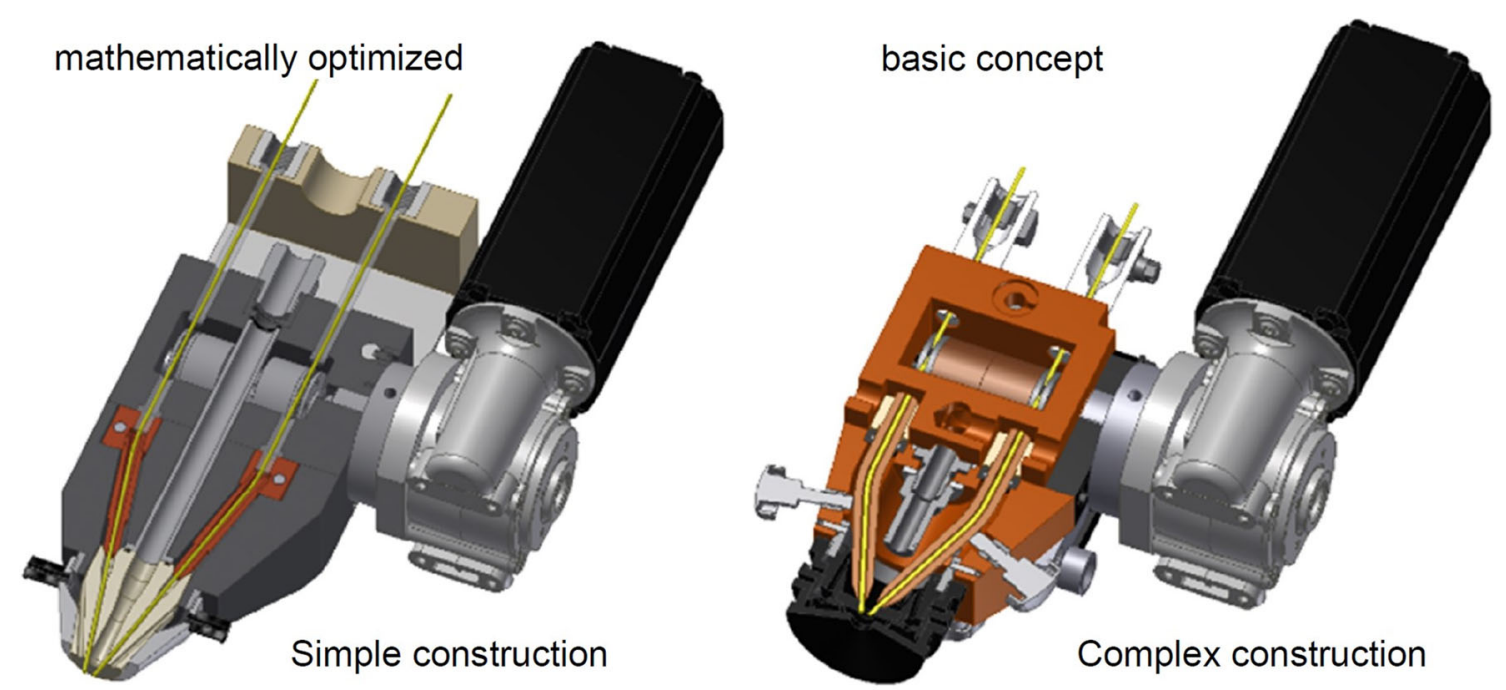

Fig. 4 Comparison of torch concepts for arc spraying. New, open version with Laval contour (high-speed version; left). Closed system with diffuser nozzle (standard variant; right) (Ref 29)

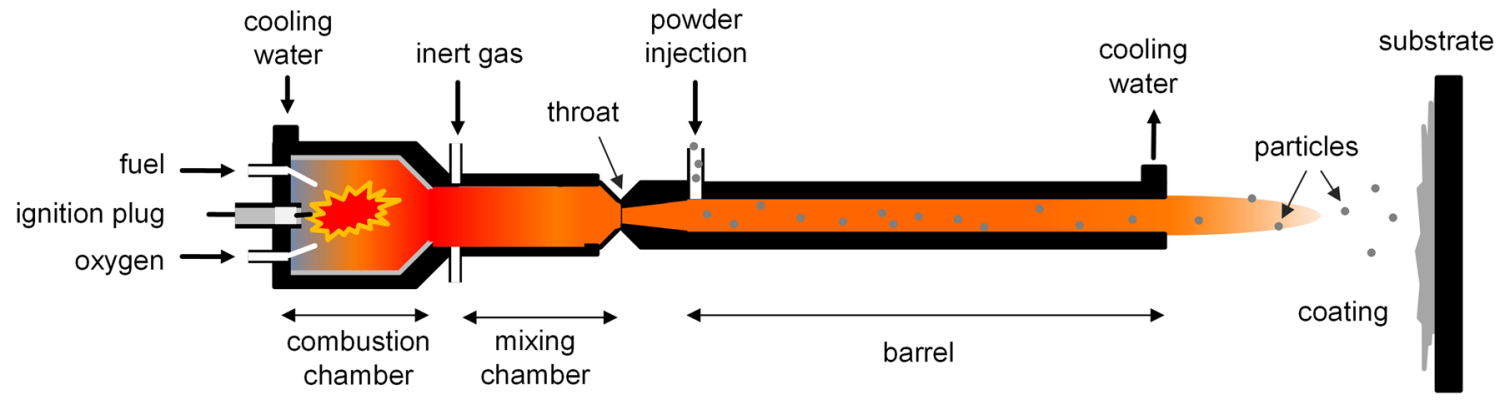

Fig. 5 Schematic of the warm spray process (Ref 5)

Considering the seawater resistance and boundary conditions for processing by thermal spraying or cold spraying, the required properties are best ensured by nickel aluminum (NAB; e.g., CuAl10Fe5Ni5) and manganese aluminum (MAB; e.g., CuMn13A18Fe3Ni3) bronzes, which are widely used in ship propeller construction (Ref 5, 32).

\section{Testing Procedures}

\section{Coating and Substrate Materials}

Powders and wires of the highly cavitation erosion-resistant bulk propeller alloys $\mathrm{CuAl10Fe} 5 \mathrm{Ni} 5$ or $\mathrm{CuAl} 9 \mathrm{Ni} 5$ Fe4Mn (NAB) and CuMn13A18Fe3Ni2 (MAB) were used as coating materials for the four different spray techniques under investigation. For cold spraying, also CuSn10 and CuNi15Sn8 as feedstock materials were investigated for balancing between high amounts of bonded interface and slightly lower coating hardness than achievable by NAB and MAB as deposit material. These tests with the softer bronzes aimed to provide a benchmark for coating properties achievable by cold spraying in relation to those of bulk materials and were carried out in the beginning of the project work. The powder sizes used for cold, warm and HVOF spraying were in a range of $25-45 \mu \mathrm{m}$ and produced by electrode induction melting gas atomization (TLS-Technik, Bitterfeld, Germany). In some cases, heat treatments of the powders before the coating process $(1 \mathrm{~h}$ at $600{ }^{\circ} \mathrm{C}$ for NAB medium and $7 \mathrm{~h}$ at $600{ }^{\circ} \mathrm{C}$ for NAB soft) were applied to ensure better deformability. In addition, also selected coatings were annealed $\left(1 \mathrm{~h}\right.$ at $500{ }^{\circ} \mathrm{C}$ and 650 ${ }^{\circ} \mathrm{C}$ ) for increasing the amounts of bonded internal interfaces. All heat treatments were performed in a high-vacuum oven of type VHT8/18 (Nabertherm, Lilienthal, Germany; vacuum of $2 \times 10^{5}$ bar and cooling rates of 10 ${ }^{\circ} \mathrm{C} / \mathrm{min}$ ). The wires for arc spraying had a diameter of 1.6 $\mathrm{mm}$ and corresponded to the designations LNM CuAl8Ni6 (Lincoln Electric, Essen, Germany) for NAB and A300 (Bedra Bercoweld, Heuchelheim, Germany) for MAB.

Shipbuilding steel VL-A (corresponding to at least S235 JR according to EN 10025-2) and for selected experiments also aluminum bronze (corresponding to $\mathrm{CuAl10 \textrm {Fe } 5 \mathrm { Ni } \text { ) }}$ served as substrate materials. The rectangular dimensions 
were approx. $50 \times 65 \mathrm{~mm}$ with a thickness of 5 or $15 \mathrm{~mm}$ for steel and approx. $35 \times 75 \mathrm{~mm}$ with a thickness between 4 and $7 \mathrm{~mm}$ for aluminum bronze. Prior to the spray processes, the substrates were grit-blasted by using $\mathrm{Al}_{2} \mathrm{O}_{3}-$ corundum. An angular blasting angle of $<45^{\circ}$ to the surface ensured efficient removement of oxide scales and surface roughening, whereas avoiding the incorporation of corundum into the surface (Ref 12 ). In addition, the substrate surface was preheated to $>80{ }^{\circ} \mathrm{C}$ in selected cases before coating. This was carried out by means of a single or double pass with the HVOF system without material flow and in cold spraying by using inductive heating.

\section{Spraying Equipment}

The spray parameter sets were individually optimized for each process and material with regard to high cavitation erosion resistance. Respective details are given in literature (Ref 5-7, 27, 33, 34).

For cold spraying, a cold spray system HSU 8000-X (prototype for the commercial Kinetiks 8000 from CGT, Ampfing Germany) was used. The variation concerned the type of process gas, type of nozzle and mainly the process gas temperatures to reach high ratios $\eta$ of particle impact velocities to critical velocities.

For HVOF spraying, a DJ 2700 gun (Oerlikon Metco, Wohlen, Switzerland) was operated with ethylene as fuel. Parameters were optimized by variation of the oxygen to fuel ratio $\lambda$, the type of cooling gas and the spray distance.

The warm spray equipment used in these investigations originally corresponds to a modified HVOF JP5000 system (Praxair Technology, Indianapolis, USA), which can combust kerosene and oxygen at different combustion pressures, and utilizing different barrel lengths for particle acceleration. In 2011, a high-pressure version of warm spray equipment was developed through collaboration of NIMS, Kagoshima University and Plasma Giken, which significantly raised the particle velocities to ranges being comparable to He-driven cold spraying (Ref 31). According to previous optimization, the stoichiometric oxygen to fuel ratio, as well as robot speed, stand-off distance and line off-set were kept the same (Ref 7). During optimization of bronze coating properties, specifically nitrogen flow rates, combustion chamber pressures were varied. In addition, for some experiments the substrates were preheated by a resistance heater to $300{ }^{\circ} \mathrm{C}$ before coating deposition.

For arc spraying, a Smart Arc system and the PPG torch equipped with the high-velocity air cap (Oerlikon Metco Europe GmbH, Kelsterbach, Germany) were used. During optimization, the main spray parameters were kept constant, while the traverse speed of the robotics (plus the number of passes) as well as the atomizing gas and spray pattern were varied and optimized.

\section{Cavitation Erosion Resistance}

The cavitation erosion resistance was determined according to ASTM G32-16 (indirect arrangement, distance from sample to sonotrode $0.5 \mathrm{~mm}$, frequency of $20 \mathrm{kHz}$, peak-topeak amplitude of $50 \mu \mathrm{m}$ ) using two different systems (Hielscher UIP 1000, Teltow, Germany; KLN BK101Z, Heppenheim, Germany), the principle being illustrated in Fig. 6. In order to avoid effects of loosely bound particles, the surfaces were stepwise ground and polished (down to using diamond abrasive grit $<4 \mu \mathrm{m}$ ). The material removal, determined by weighing after increasing, material-dependent time intervals, was converted into the respective erosion depth considering the eroded surface area and the material density. The cavitation resistance was determined as maximum erosion rate (MER) and terminal erosion rate (TER). The schematics in Fig. 6 include a description of possible analyses methods. The original data presented in the different single studies (Ref 5$7,27,33,34)$ were re-evaluated for gaining an uniform description of the results obtained on different equipment.

Data evaluation regarding the maximum erosion rate (MER) and terminal erosion rate (TER) could lead to slightly different rankings for the long-term durability of a tested material. During the investigations, it was found that thermally and kinetically sprayed coatings show distinct peak values at the beginning of the exposure period, which are often many times higher than the rapidly emerging terminal erosion rate and will be presented in the further sections for the optimized coatings. As a measure for the long-term durability of the coatings, the terminal erosion rate is therefore more suitable, since it is more representative for the material behavior. Considering the differences in the data (exposure time, intervals etc.) regarding the final technological comparison, the terminal erosion rate was determined uniformly for exposure times greater than $60 \mathrm{~min}$ (second half of the overall test duration of 120 min) for all thermal spray coatings and the cast reference materials, see section "Process Selection and Achievable Coating Properties." Even though the true TER for bronze coatings could probably be lower and reached only after longer test durations, the determined data in the time interval between 60 and $120 \mathrm{~min}$ are considered as suitable to indicate the long-term trends and to relate them to the other deposit properties. Additionally, the erosion depth (MDE), i.e., conversion of the material loss into volume loss, and the instantaneous erosion rates over exposure time were determined for the optimized coatings. In contrast, for the bronze materials that were previously examined using cold spraying for the initial material optimization, the TER 


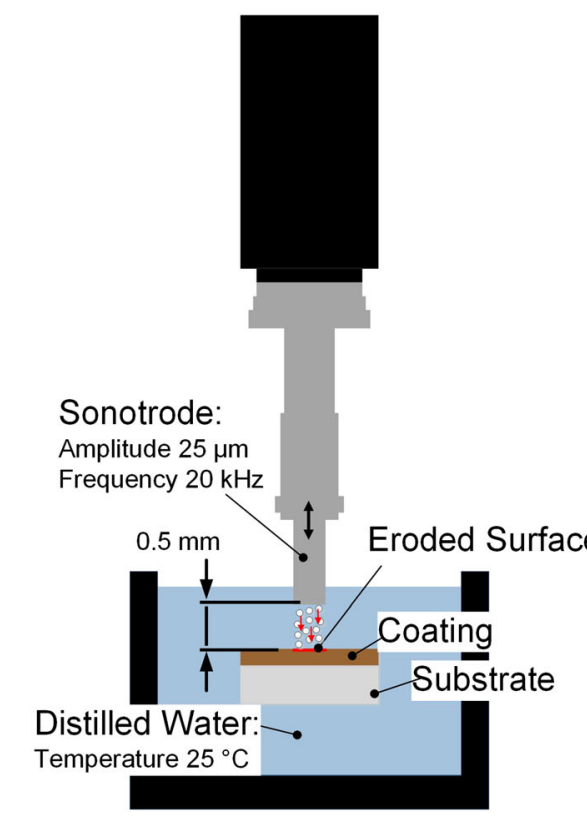

(a)

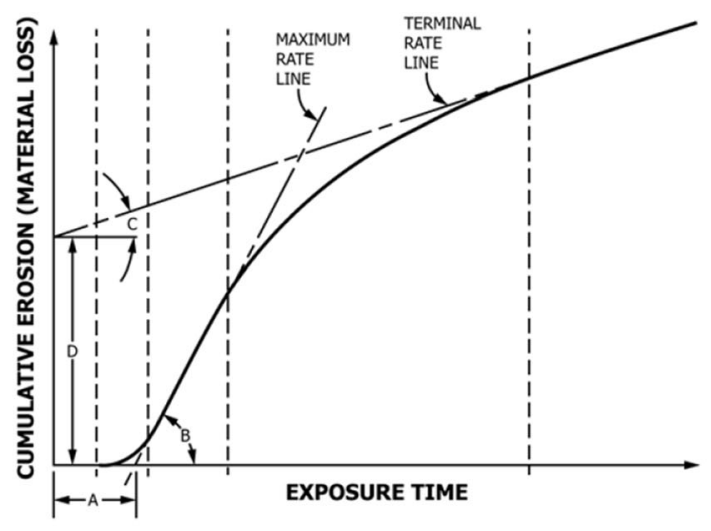

(b)

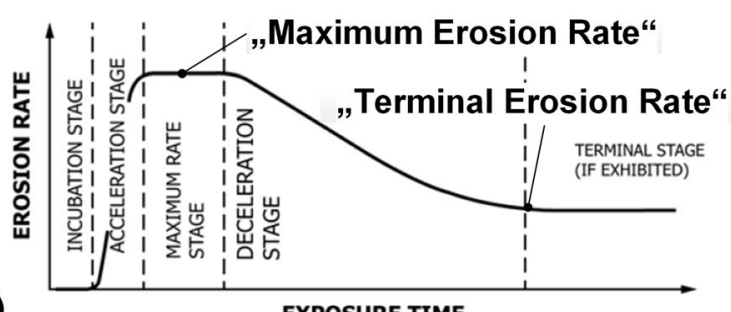

Fig. 6 (a) Cavitation erosion test according to ASTM G32-16 (indirect method). All test parameters are nominal values; the tolerances are listed in the standard. (b) Schematic phases in the erosion-time curve and characteristic parameters in the test procedure (Ref 2)

was determined after a test duration of 300 min (covering exposure times longer than $150 \mathrm{~min}$ ), see section "Material Optimization for Cold Spraying."

\section{Mechanical Coating Properties}

Faced with coating thicknesses in the range of a maximum of one millimeter set by thermal spraying and cold gas spraying, mechanical coating properties were determined on miniaturized flat tensile specimens (micro flat tensile test) with gage dimensions of $0.5 \mathrm{~mm}$ in thickness, $12 \mathrm{~mm}$ in length and $2 \mathrm{~mm}$ in width (Ref 5, 35). In order to ensure low surface roughness $(\mathrm{Rz}<30 \mathrm{~mm}, \mathrm{Ra}<4 \mu \mathrm{m})$, these samples were produced by wire electrical discharge machining. The test was load-controlled with an increase of $2 \mathrm{~N} / \mathrm{s}$ on a tensile testing machine (Zwick/Roell, Ulm, Germany).

\section{Tensile Adhesive Strength}

The tensile adhesive strength was measured on roughened surfaces according to (Ref 36$)$. Coated cylinder faces ( $\varnothing 25$ $\mathrm{mm}$ ) were glued (Ultrabond 100, HTK Hamburg GmbH, Hamburg, Germany) against surface roughened counterparts of same dimensions. The tests were performed loadcontrolled with an increase of $2 \mathrm{~N} / \mathrm{s}$ and carried out in a static uniaxial testing machine (Zwick Roell Z50, Ulm, Germany) with minimum three specimens each.

\section{Specific Electrical Conductivity}

The specific electrical conductivity of the cold-sprayed, warm-sprayed and HVOF-sprayed coatings was determined by the eddy current method using a Sigmascope SMP10-HF and a measuring sensor ES40HF (both: Helmut Fischer GmbH, Sindelfingen, Germany) in accordance to (Ref 37) with a frequency of $1250 \mathrm{kHz}$ to ensure a low skin depth. In order to avoid influences of the surface topology and loosely bonded splats, the specimens were ground before testing. Minimum 10 readings were recorded for determination of the mean conductivity by eddy current analyses.

For arc spraying and the bulk substrate material, the conductivity was determined using the four-terminal measuring method (Loresta GX MCP-T700, Mitsubishi Chemical Analytech Co. LTD, Kanagawa, Japan) by investigating 3 different areas and recording 7 values each. In this method, the determined ohm resistivity is converted into the specific resistivity by multiplication with a correction factor RCF (depending on geometry and measuring position) and the corresponding coating thickness or, as an inverse value, into the electrical conductivity. For the measurement of aluminum bronzes, constant currents of 0.1-1 A were suitable. The test method allows for measuring the electrical conductivity in the as-sprayed and aspolished states. 


\section{Coating Hardness}

In case of the cold-sprayed, warm-sprayed and HVOFsprayed coatings, hardness was measured by using a Miniload II (Leitz, Stuttgart, Germany) on polished cross sections as HV 0.3 (applied load $2.9 \mathrm{~N}$ ). The hardness of the arc sprayed coatings was measured on the polished surfaces as HV 1.0 by using a Wolpert 432 (Wilson Wolpert Instruments, Aachen, Germany; applied load 9.8 N). Following (Ref 12), at least 10 measured values were recorded. Subsequently, the maximum and minimum values were deleted before determining the average value. Apart from this, the guidelines specified in (Ref 38) apply.

\section{Microstructure and Porosity}

Coating quality was investigated by microstructural analyses using optical microscopes (OM) Leica DM6000M and DMRM with the software tools AxioVision ${ }^{\circledR}$ (all Leica Microsystems GmbH, Wetzlar, Germany) and the program ImageAccess (Imagic Bildverarbeitung AG, Glattbrugg, Switzerland). Scanning electron microscopy (SEM) was performed using a JEOL JSM-IT100 (JEOL Germany $\mathrm{GmbH}$, Freising, Germany; acceleration voltage $10 \mathrm{kV}$, backscatter detector) and a Quanta 650 (FEI, Brno, Czech Republic; acceleration voltage of $20 \mathrm{kV}$ ). The specimens for metallographic examinations were hot-mounted via ATM Opal 410 Hot Mounting Press (ATM GmbH, Mammelzen, Germany) and gradually ground and polished (6 $\mu \mathrm{m}, 3 \mu \mathrm{m}$ suspensions, finally using oxide polish OPS). For representative phase analyses, Klemm III color etchant (stock solution: sodium thiosulfate in water; etching solution: potassium pyrosulfite) was used for selected specimens to improve contrasts. The exact coating thickness of the specimens, which can be found in Table 5, was determined in the cross sections using five measurements each. Using suitable programs (KS300, Zeiss, Jena, Germany and ImageJ, National Institutes of Health, USA, in region of interest also Despeckle filter and binarization via histograms), the porosity fractions were quantitatively evaluated according to (Ref 39).

\section{Oxygen/Oxide Content}

Global oxygen contents were quantitatively determined on detached coating components (cold, warm and HVOF spraying) by hot gas extraction (analyzer type G8 Galileo, Bruker, Germany). Due to the comparatively higher amounts being present, the oxygen content of the arc sprayed coatings was determined by means of energy dispersive $x$-ray analysis (EDS; JEOL Dry SD25 detector, JEOL Germany GmbH, Freising, Germany; acceleration voltage $15 \mathrm{kV}$ ) by carrying out 3 measurements each.
Although not being as exact as other methods, the determination by EDS for the case of arc sprayed coatings appears as a good compromise to detect both light and heavy elements at the same time.

\section{Descriptions of the Spray Processes and their Optimization}

\section{Cold Spraying}

Generally, in cold spraying, coating quality can be optimized by an increased ratio of impact velocities over critical velocities, here defined as $\eta$-values (Ref 11 ). Respective data on impact conditions, means particles velocities and temperatures as well as critical velocities for bonding were calculated by a commercial software package (KSS, www.kinetic-spray-solutions.com). One option to increase $\eta$-values is increasing impact parameters by tuning gas temperature, pressure or using other types (Ref $5,11)$. For applying this $\eta$-concept, spray powders should ideally have similar properties as the bulk material. However, powder production by inert gas atomization often results in fine microstructures due to the very rapid solidification of the molten droplets to solid particles, which then have higher strength than conventionally cast material (Ref 40). In the case of alloys, it must also be taken into account that rapid solidification can enhance the formation of metastable phases with significantly higher strengths as compared to that of the equilibrium structures of casted alloys. This makes deformation on impact more difficult, results in higher critical velocities and reduces adjustable coating quality. In the case of highly alloyed $\mathrm{Cu}$ materials like Ni-Al bronze (NAB), such powder properties, in case of partial martensite formation even a reduced plasticity (Ref 11, 40), can severely impede processing by cold spraying (Ref 5, 40). In order to achieve acceptable coating properties, such powders can be annealed in a separate process step (Ref 33$)$.

As an example, Fig. 7 shows the calculated impact conditions, i.e., impact velocities and temperatures of NiAl bronze powders for three diameters (D10, D50, D90) of the used spray feedstock by the three circles in comparison with the critical velocities given by the three curves for different pre-treatments and thus mechanical strengths of the powders (Ref 5). The calculations of the critical velocities in Fig. 7 are based on experimentally determined powder strengths and can be found in detail in (Ref 5). Principles for measuring powder strengths are given in (Ref 40).

The impact conditions and the critical velocities were calculated by using the KSS-software package. By their smaller momentum, smaller particles are accelerated to 
higher velocities than larger ones. Under ideal conditions, all particles reach the gas temperature before passing though the nozzle throat. However, by their smaller thermal momentum the smaller particles cool down to significantly lower temperatures than the larger ones during travelling in the expanded and rapidly cooled gas reaching the expanding nozzle regime and the free jet. For uniform coating formation, impact conditions for a given size distribution are tuned by preheating in an elongated prechamber to result in similar $\eta$-values for a given size distribution. However, for cold spraying of NAB, there are practical limits that restrict the application of the full potential of modern cold spay equipment. For cold spraying of nickel-aluminum bronzes, an increase of the process gas temperatures to above $650{ }^{\circ} \mathrm{C}$ is practically not useful, since even water-cooled WC-Co nozzles at such higher temperatures suffer from clogging by the spray powder (Ref 5). Higher $\eta$-values are only achievable by using helium as propellant gas, as the velocity of sound is larger than for nitrogen, and thus also particle velocities. However, the associated costs would be very high. Thus, the optimization for increasing $\eta$-values followed two approaches. On the one hand, particle sizes and impact conditions were tuned to maximum, and on the other hand, the material's strength and thus the critical velocity were minimized by heat treatments prior to spraying. Results of this strategy are shown in Fig. 8. Table 1 summarizes the parameters that were worked out as ideal for the production of nickel-aluminum bronze coatings by cold spraying.

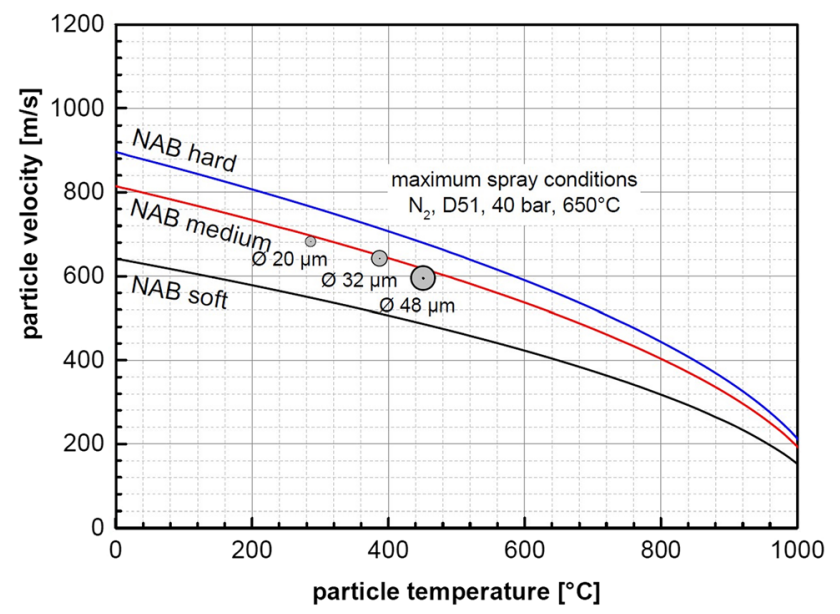

Fig. 7 Particle impact conditions corresponding to the typical size distribution of $\mathrm{Ni}-\mathrm{Al}$ bronzes to be used in cold spraying in comparison with critical velocities for a coating formation. The critical velocities are calculated for powders in as supplied state (hard) and for additionally heat-treated powders at $T=600{ }^{\circ} \mathrm{C}$ (annealing time $1 \mathrm{~h}$ : medium, annealing time $7 \mathrm{~h}$ : soft) (Ref 5). The maximum spray conditions account for untreated NAB powder

\section{HVOF Spraying}

For HVOF spraying of nickel-aluminum bronzes, settings with an oxygen to fuel ratio $\lambda$ of about 0.7 proved to be optimum for needed coating qualities, because this allows for sufficiently good, partial melting of the powder. For calculating the oxygen to fuel ratios $\lambda$, the original data from (Ref 5) were re-evaluated. In case of using air as cooling gas, respective oxygen contents are considered not to contribute to the combustion. Fig. 9 shows the cavitation erosion rates of coatings produced with different oxygen to fuel ratios $\lambda$ and spraying distances. If the particle impact temperature is too low, this results in insufficient bonding between the individual splats that form the coating. If the particle or droplet temperature is too high, oxidation can restrict bonding between spray splats. As reported in (Ref 5 ), in case of using nitrogen as coolant, coating porosity decreases with $\lambda$, and then stays constant at about $1 \%$ at $\lambda$ $>0.65$. At $\lambda<0.7$, coating oxygen contents are rather low with about $0.1 \mathrm{wt} . \%$, but for higher values show a fast increase. In consequence, highest electrical conductivity and mechanical strengths are obtained for $\lambda$ of about 0.7 . In case of using air as coolant, coating porosities and oxygen contents are significantly by two to five times higher, resulting in slightly lower coating conductivity and strength. This means that higher flame and thus droplet temperatures already within reducing ('rich') conditions for combustion and an oxygen enriched environment lead to oxidation levels that limit coating performance. As reported in (Ref 5), the slight advantage of larger spray distances for reaching better cavitation resistance can be explained by lower particle or droplet temperature and a semi-molten or solid state being beneficial for optimum deposit properties leading to slightly less oxidation. At the higher SOD, the individual particle velocities are already influenced by deceleration and are thus slightly lower, but range over a rather narrow regime for all particle sizes, which could support a more uniform coating formation. Reported coating porosities thus decrease with increasing SOD.

With oxygen contents of only about 0.1 wt.\% in the optimum built-up deposits, the individual splats within the coatings are sufficiently well bonded to ensure a cavitation erosion resistance, which is only about a factor of two lower as compared to that of the bulk material.

The manufacturing parameters for optimum cavitation erosion protection using HVOF-sprayed nickel-aluminum bronzes for both cooling gases are subsequently summarized in Table 2. Overall, however, parameter HVOF 1 with nitrogen as cooling gas guarantees for the best cavitation resistance of the different HVOF coatings. 
Fig. 8 Mean erosion depths as function of adjusted coating quality parameters $\eta$. Powder annealing and thus reduced powder strength enables reaching high coating qualities. The inserts show the surface damage obtained after a cavitation testing time of 100 $\min$

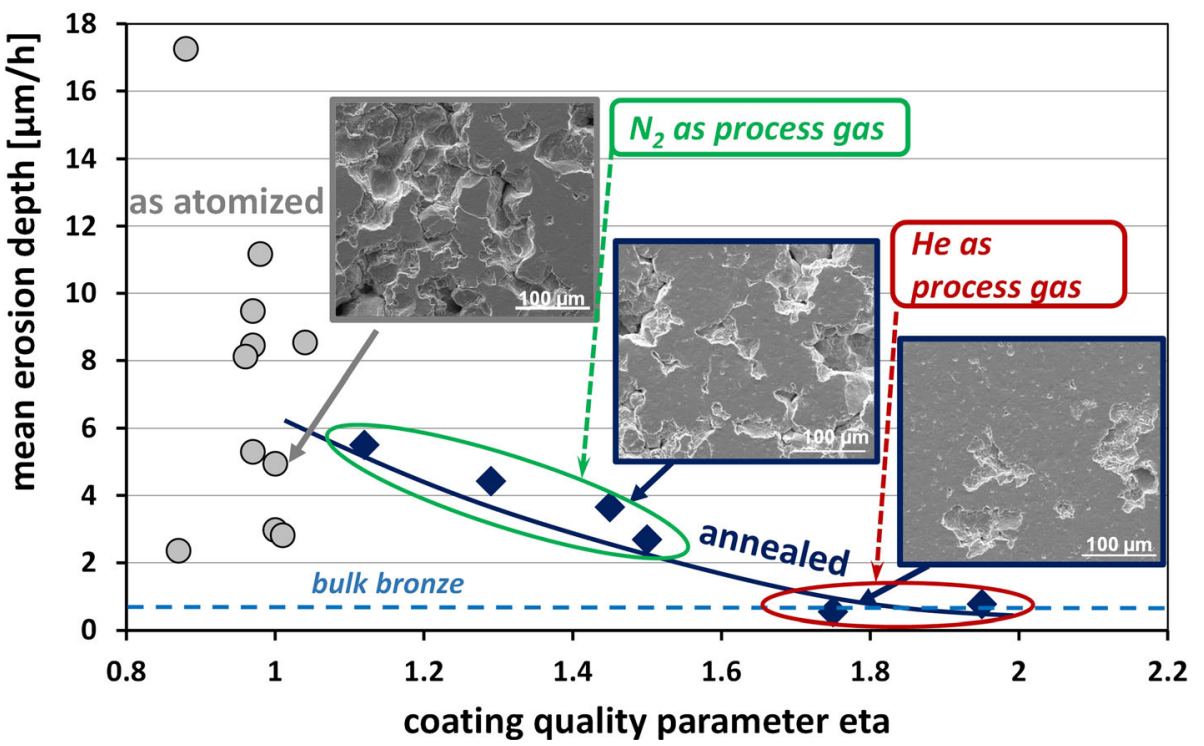

Table 1 Optimized spray parameters and possible heat treatment variations for cold spraying of CuAl10Ni5Fe5 (NAB)

\begin{tabular}{lllll}
\hline Parameter & \multicolumn{2}{c}{ CS 1} & \multicolumn{1}{c}{ CS 2} & CS 3 \\
\hline Substrate material & Steel VL-A & Steel VL-A & Steel VL-A & Steel VL-A \\
Powder pre-treatment & $\ldots$ & Tempered, $7 \mathrm{~h}$ at $600{ }^{\circ} \mathrm{C}$ & Tempered, $7 \mathrm{~h}$ at $600{ }^{\circ} \mathrm{C}$ & Tempered, $7 \mathrm{~h}$ at $600{ }^{\circ} \mathrm{C}$ \\
Process gas & $\mathrm{N}_{2}$ & $\mathrm{~N}_{2}$ & $\mathrm{~N}_{2}$ & $\mathrm{He}$ \\
Nozzle type & $\mathrm{D} 51$ & $\mathrm{D} 51$ & $\mathrm{D} 51$ & $\mathrm{D} 24$ \\
Process gas pressure, bar & 40 & 40 & 40 & 30 \\
Process gas temperature, ${ }^{\circ} \mathrm{C}$ & 650 & 650 & 700 & 650 \\
Powder feed rate, $\mathrm{kg} / \mathrm{h}$ & 2.4 & 2.4 & 2.4 & 2.4 \\
Stand-off distance, $\mathrm{mm}$ & 60 & 60 & 60 & 60 \\
Robot traverse speed, $\mathrm{mm} / \mathrm{s}$ & 400 & 400 & 400 & 400 \\
Coating post-treatment & $\ldots$ & Tempered, $1 \mathrm{~h}$ at $500{ }^{\circ} \mathrm{C}$ & $\ldots$ & $\ldots$
\end{tabular}

\section{Warm Spraying}

As for HVOF-spraying, attainable coating qualities by warm spraying are influenced by nozzle length, combustion pressure, as well as kinematic parameters, such as stand-off distance, traverse speed, powder feed rates and powder properties (density, size distribution, morphology). However, the major influence on particle temperatures is given by the nitrogen flow rates added as cooling gas into the mixing chamber (Ref 5,33). The results presented hereafter are mainly based on a variation of the nitrogen flow rate and the combustion pressure. Additional influence on coating build-up is given by the mechanical and thermal properties of the substrate, influencing adhesion. For building up thicker coatings on steel plates with a thickness of $10 \mathrm{~mm}$, preheating of the substrates to a temperature of
$300{ }^{\circ} \mathrm{C}$ was needed. In contrast to the parameters that are commonly used for comparing the results in coating performance (e.g., nitrogen flow rate or the ratio of particle velocity to critical velocity), an energy-based approach is used in the following according to (Ref 5,11$)$ and in analogy to the parameter $\eta$ for cold spraying. This relative impact energy summarizes the kinetic and thermal energy of the particle in the spraying process (Ref 5,11).

Figure 10 summarizes the cavitation rates of warmsprayed NAB coatings as function of relative impact energy. The results show that high relative impact energies could sufficiently decrease material losses by cavitation erosion, under ideal conditions guaranteeing a similar performance as for cast bulk material. Even if the technology is not yet available on the market, the optimum parameters are listed for comparison in Table 3. 


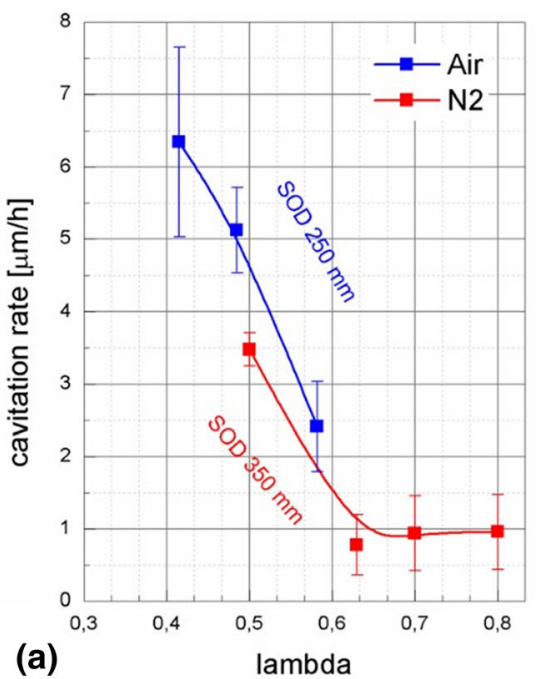

(a)

lambda

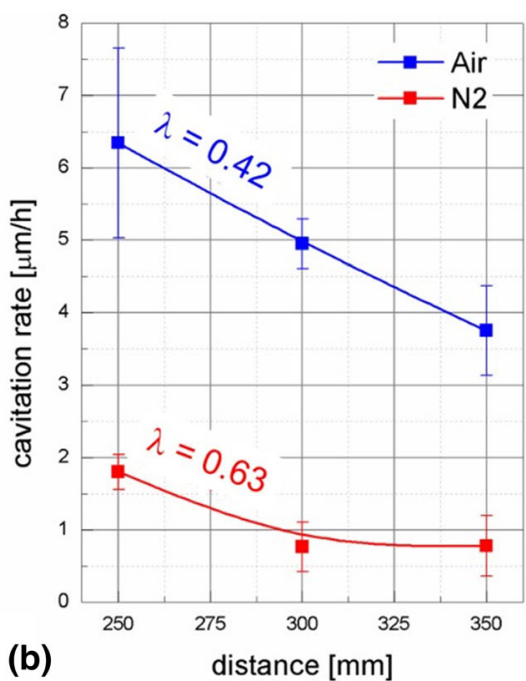

(b)

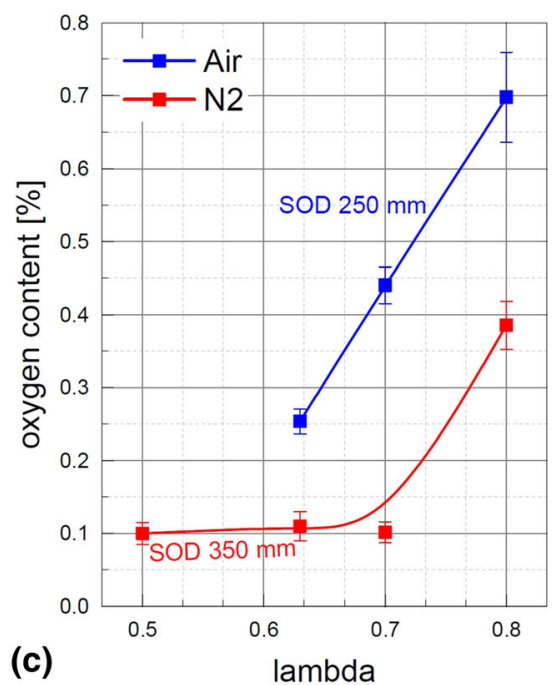

Fig. 9 Cavitation erosion rates as a function of the oxygen to fuel ratio $\lambda$ (a) and the spraying distance (b). In (c), the oxygen content is presented as a function of the oxygen to fuel ratio $\lambda$. Experimental results are replotted from (Ref 5), the oxygen to fuel ratios being recalculated. For the use of nitrogen as cooling gas, the arrows indicate the optimum compromise between the different coating properties
Table 2 Optimized spray parameter sets for $\mathrm{HVOF}$ spraying of $\mathrm{CuA} 110 \mathrm{Ni} 5 \mathrm{Fe} 5$ (NAB)

\begin{tabular}{lll}
\hline Parameter & HVOF 1 & HVOF 2 \\
\hline Substrate material & Steel VL-A & Steel VL-A \\
Powder pre-treatment & $\ldots$ & $\ldots$ \\
Flow rate fuel (ethane), 1/min & 110 & 110 \\
Flow rate oxygen, 1/min & 232 & 192 \\
Cooling gas type/flow rate in 1/min & $\mathrm{N} 2 / 360$ & Compressed air/360 \\
Oxygen/fuel ratio $\lambda$ & 0.7 & 0.58 \\
Powder feed rate, $\mathrm{kg} / \mathrm{h}$ & 4.5 & 4.5 \\
Stand-off distance, $\mathrm{mm}$ & 350 & 250 \\
Robot traverse speed, $\mathrm{mm} / \mathrm{s}$ & 667 & 667 \\
Coating post-treatment & $\ldots$ & $\ldots$
\end{tabular}

\section{Arc Spraying}

For arc-sprayed coatings, the results under optimization procedures proved that residual stresses can significantly affect respective cavitation erosion resistance. These stresses are usually of tensile nature, if standard industrial conditions are used by applying compressed air as atomization gas (Ref 26). However, the corresponding residual stresses can be reduced considerably, for example by using alternative atomizing gases or by adapting the robot kinematics (Ref 6,27). In addition, the type of substrate material and the substrate dimensions plays a major role for the stress development and in consequence the final coating properties (Ref 34). Thus, in addition to standard parameter sets, here serving as a reference, major focus concerned the identification of most favorable atomizing gases, as well as the optimization of the kinematics for different substrate types. Both was found to severely influence coating build-up and the final coatings properties (Ref 6, 26, 27). The atomizing gas affects the temperature during layer by layer deposit build-up and by this also the phase composition and the resulting residual stresses. All these factors in turn affect cavitation resistance (Ref $6,26,27)$. The process kinematics influence these in a similar way. Thus, for more uniformly heated specimens produced with pressurized air, almost similar cavitation resistances were found as for spot-heated specimens produced with nitrogen (Ref 6). In addition, also the substrate material plays a role, which can be seen in the better cavitation resistance, when using NAB instead of steel as substrate under the same kinematics and pressurizing gas (Ref 34). The optimized parameter sets identified by these variations are given in Table 4.

Further details can be found in various publications (Ref $6,26,27,34)$. For the case of thicker coatings than specified under the present scope by adjusting the number of 


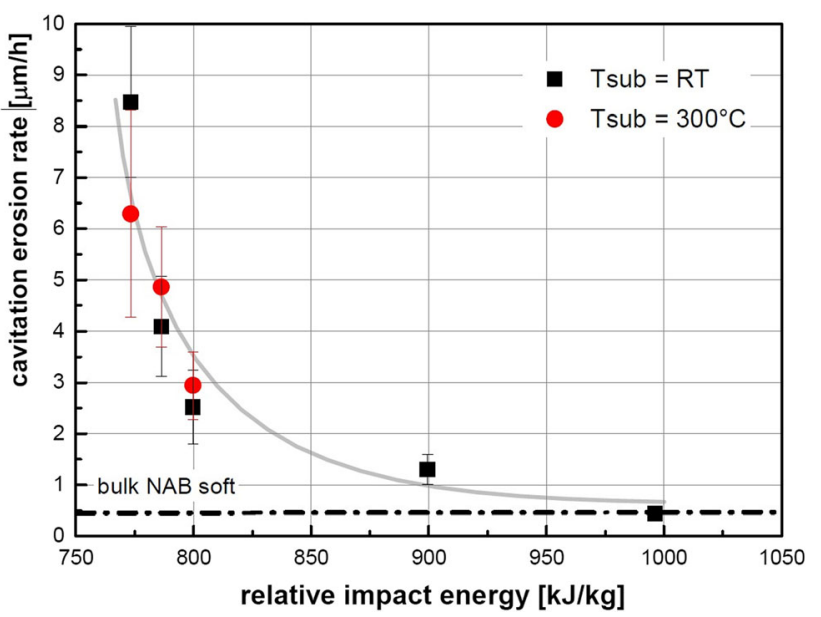

Fig. 10 Cavitation erosion-rate of the warm-sprayed bronze coatings as a function of the relative impact energy on pre-heated and not preheated substrates according to (Ref 5). For comparison, the measured cavitation rate of the respective bulk Ni-Al-bronze is given as a straight line

Table 3 Optimized spray parameter sets for warm spraying of CuAl10Ni5Fe5 (NAB)

\begin{tabular}{ll}
\hline Parameter & \multicolumn{1}{c}{ WS } \\
\hline Substrate material & Steel VL-A \\
Substrate pre-treatment & $\ldots$ \\
Powder pre-treatment & $\ldots$ \\
Pressure type/size in $\mathrm{MPa}$ & High pressure/4 \\
Flow rate kerosene, $1 / \mathrm{min}$ & 0.98 \\
Flow rate oxygen, $1 / \mathrm{min}$ & 480 \\
Flow rate nitrogen (mixing chamber), 1/min & 500 \\
Powder feed rate, $\mathrm{kg} / \mathrm{h}$ & 3.72 \\
Stand-off distance, $\mathrm{mm}$ & 200 \\
Robot traverse speed, $\mathrm{mm} / \mathrm{s}$ & 700 \\
Coating post-treatment & $\ldots$ \\
\hline
\end{tabular}

Table 4 Optimized spray parameter sets for arc spraying of CuAl10Ni5Fe5 (NAB)

\begin{tabular}{lll}
\hline Parameter & \multicolumn{1}{c}{ AS 1 } & \multicolumn{1}{c}{ AS 2 } \\
\hline Substrate material & Steel VL-A & Ni Al bronze \\
Arc voltage, $\mathrm{V}$ & 28 & 28 \\
Arc current, A & 180 & 180 \\
Wire feed rate, $\mathrm{kg} / \mathrm{h}$ & 7.2 & 7.0 \\
Atomizing gas & $\mathrm{N}_{2}+2 \% \mathrm{H}_{2}$ & $\mathrm{~N}_{2}+2 \% \mathrm{H}_{2}$ \\
Primary gas pressure, bar & 4 & 4 \\
Stand-off distance, $\mathrm{mm}$ & 100 & 100 \\
Spray pattern & Spiral (from outside inward) & Meander (alternating) \\
Robot traverse speed, $\mathrm{mm} / \mathrm{s}$ & 333 & 333 \\
Number of layers & 9 & 9 \\
\hline
\end{tabular}

spray passes, special care is needed to limit residual stresses and possible coating delamination.

\section{Technological and Economical Coating Characterization}

The aim of this chapter is to supply information on the cavitation erosion resistance of bronze coatings as attainable by using different spray processes. For direct comparison and easier choice by the end user, respective data are related to those of bulk propeller bronze NAB or shipbuilding steel VL-A. With respect to influences by properties of different bronze types, particularly the part on cold spraying addresses required boundary conditions. As additional guidance for applications, rough estimates of relative costs for coating production are compared in the first paragraph.

\section{Rough Estimation of Coating Costs}

For cold spraying, possible costs for bronze coating production were estimated by the economy tool of the KSS software package, including all different variable and fixed costs being associated with the process. This tool was also adopted for giving an estimate on costs of HVOF-spraying. For arc-spraying, possible costs were calculated separately, but as well included all the different input data. The respective results for all methods were then cross-checked with quotations from industries. However, coating costs are subject to fluctuations in raw material prices, individual expenses for depreciation, spray booth, wages, etc. and are therefore also influenced by regional differences. For this reason, absolute prices cannot be given. Nevertheless, it is possible to evaluate the costs of different processes in a relative comparison. The relative cost comparison relates to a flat component (e.g., part of a ship's rudder), which is 
coated with aluminum bronze in a thickness of $0.5 \mathrm{~mm}$, covering an area of one square meter. The price per unit is dominated by the variable costs, i.e., spray material, gases, energy, for all the processes mentioned. Accordingly, individual deposition efficiency is an important control variable. For the estimation, it was also assumed that the material feedstock and process gases are procured in large quantities with respective discounts. The costs also include substrate preparation by corundum blasting. Costs for possibly useful powder annealing or subsequent annealing of the coatings are not included in the comparison. The results are given as relative values as compared to $\mathrm{HVOF}$ spraying, serving as reference here. Under standard conditions, cold spraying with nitrogen as process gas and arc spraying should be capable to coat the assumed area at costs of about $87 \%$ and $48 \%$, respectively, in comparison with the costs inferred by HVOF spraying. However, these numbers are only a rough estimate and will vary by fluctuations of prices for consumables like powder and process gases as well as by regional differences in depreciation, spray booth investment and wages.

\section{Material Optimization for Cold Spraying}

Within the limited range in maximum process gas temperatures in cold spraying, attainable coating cavitation resistance can be individually tuned for maximum amounts of bonding interfaces or high deposit hardness by selection of alternative bronzes as feedstock materials. Bronzes of lower strength and thus lower critical velocities at given spray conditions allow for higher $\eta$-values and possibly bulk like coating properties, not attainable by NAB. Since non-bonded interfaces mainly affect crack growth and hardness just the general resistance against deformation, both should have different influences on cavitation resistance, and might help to identify a suitable compromise for needed coating performance. Considering also this alternative optimization route, the overall results for attainable maximum cavitation resistance by means of cold spraying are summarized in the following.

Figure 11 shows the maximum erosion rates (MER) due to cavitation during an exposure time of $300 \mathrm{~min}$ in laboratory tests, as minimized by individual parameter optimization in cold spraying for the different bronzes under investigation. In the case of $\mathrm{NAB}$, the comparison also contains data for different powder or coating treatments (compare also Table 1 and (Ref 5)). Cast Ni-Al propeller bronze (NAB) with an erosion rate of about $0.5 \mu \mathrm{m} / \mathrm{h}$ and shipbuilding steel VL-A with an erosion rate of $27 \mu \mathrm{m} / \mathrm{h}$ are given as references. The comparison demonstrates that cold spraying of NAB or MAB bronze can provide coating properties that successfully reach similar cavitation resistance as for cast propeller bronze. However, for achieving such high-end properties, helium is needed as process gas, with correspondingly high process costs. In comparison with cold spraying of as-atomized powder, the use of tempered powders in cold spraying with nitrogen as process gas improves the cavitation erosion resistance considerably, but still results in five times higher material removal rates in comparison with cast propeller bronze. However, by subsequent coating annealing, the properties can be tuned to match those of the cast bulk material. For special repair applications, mandatory powder and coating heat treatments have to be offset against costly operation with $\mathrm{He}$ as process gas to reach a bulk-like performance. For large scale production, the other alternative techniques and compromises regarding performance of the coatings need to be considered also.

Due to overall lower material strength and the lack of metastable phase being present in the atomized state, Snand NiSn-bronzes are easier to process in good coating qualities by cold spraying with nitrogen as a process gas. However, the retained plasticity and missing hardness of respective coatings restricts the needed cavitation protection. Only the rather hard MAB coatings produced with $\mathrm{He}$ as process gas reaches cavitation rates that are similar or even lower than those of cast $\mathrm{Ni}-\mathrm{Al}$ propeller bronze. Favoring NAB and MAB as the materials of choice for attaining high cavitation resistance can thus be understood by two facts; (I) the resistance of a material to cavitation erosion depends on its resistance to plastic deformation, such as material hardness (Ref 2, 41). (II) Since material removal usually occurs via crack growth, the fatigue strength must be considered as additional decisive factor (Ref 32, 42). A higher fatigue strength is associated with longer incubation periods for plastic deformation and crack nucleation as well as crack growth and thus lower cavitation erosion rates (Ref 42). The results concerning bronzes differing in material strength indicate that both criteria must be met for high cavitation resistance.

\section{Process Selection and Achievable Coating Properties}

Figure 12 shows the terminal erosion rates (TER) after 120 min exposure time in laboratory tests for $\mathrm{Ni}-\mathrm{Al}$ bronze coatings (NAB), as obtained by individual process optimization.

The two thermal spray processes, i.e., HVOF and arc spray, can ensure coating properties that satisfy the majority of possible applications in marine environments. Using high-pressure warm spraying, properties similar to those of cast propeller bronze can be achieved under optimized conditions. However, the process is not yet widely available on the market and the additional use of nitrogen as cooling gas in operation makes it more expensive than HVOF spraying. HVOF spraying cannot 


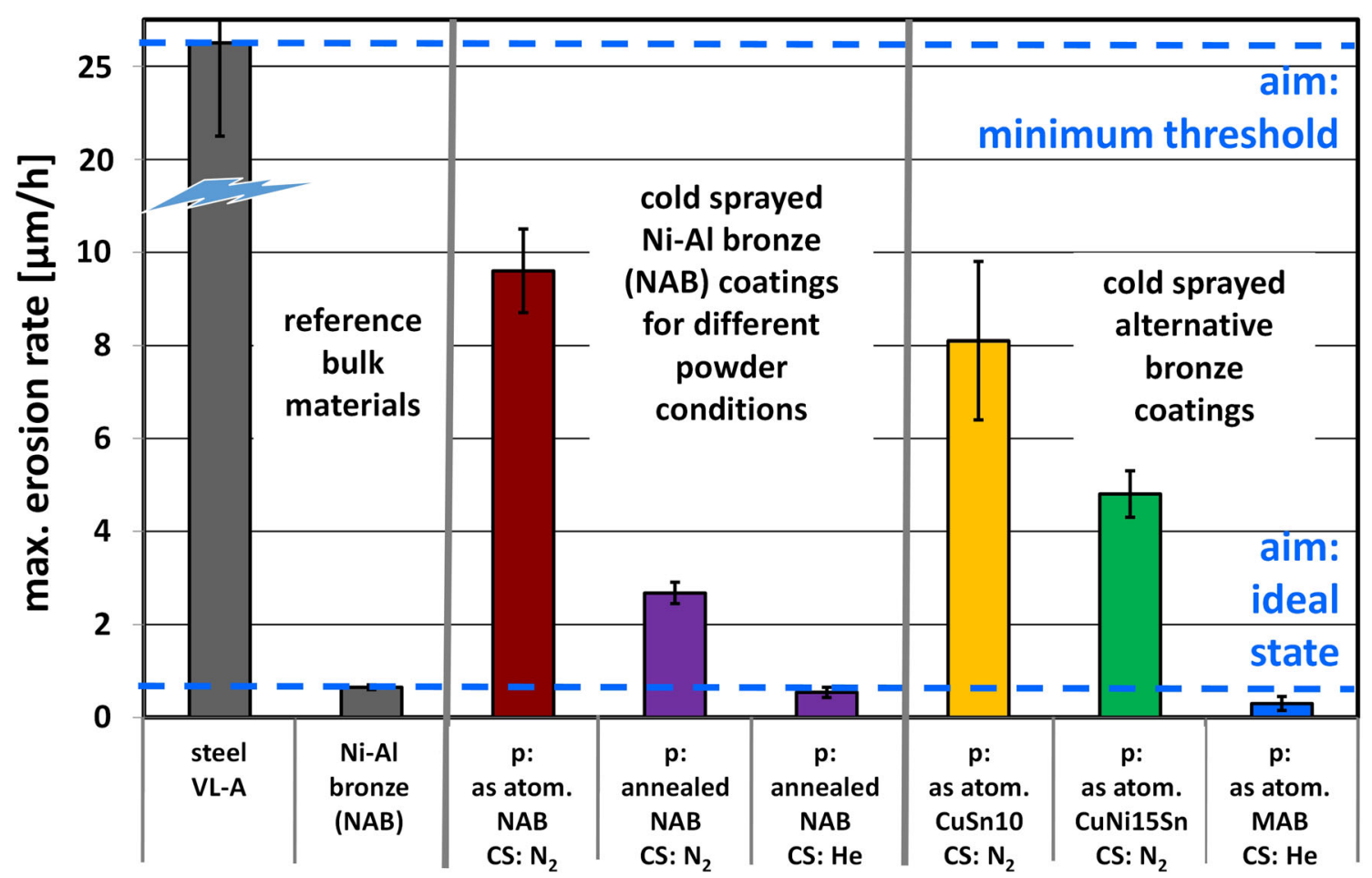

Fig. 11 Maximum erosion rates (MER) for the, respectively, optimized process conditions during cold spraying of the different bronzes after a test duration of 300 minutes (Ref 5)

Fig. 12 Comparison of the terminal erosion rates (TER) after a test duration of 120 minutes of the individually optimized spraying processes for $\mathrm{Ni}$-Al bronze coatings

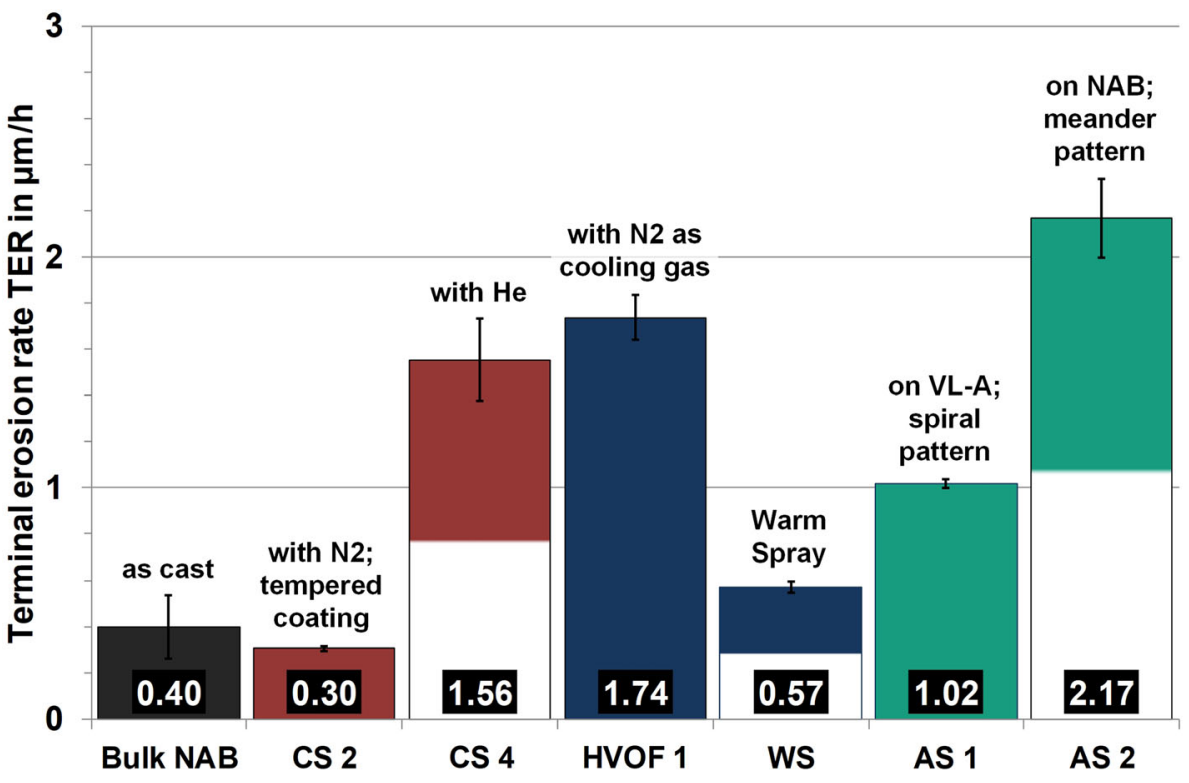

By sufficient optimization, for example by the choice of the atomizing gas as well as robot kinematics to avoid layer by layer overheating, good coating qualities can also be achieved by arc spraying. Despite inevitable oxidation, under ideal conditions, the erosion rates of respective coatings are only about three times higher than those of bulk bronze. For applications in the rudder area, it makes sense to use the commonly used shipbuilding steel VL-A as 
a reference. As compared to VL-A steel, arc-sprayed coatings show 26 times better cavitation resistance, and HVOF-sprayed coatings show about 16 times better cavitation resistance. Both should be adequate to provide satisfactory lifetimes or dock intervals with regard to ship rudder applications. With regard to the choice of process technologies for repair applications involving cavitationresistant bronze parts, it is, however, necessary to consider what residual lifetimes have to be expected.

More in depth information about associated material removal is supplied by the temporal development of erosion depths and erosion rates given in Fig. 13. The erosion depths essentially reflect the findings regarding the TER given above. However, the curves show different, timedependent slopes for the various groups of deposition methods. For example, for the parameter set cold spray with helium CS 4 and HVOF 1, it can be seen that initially very high erosion rates and depths occur, which decline after about 20-30 min and presumably in the long term (greater than $120 \mathrm{~min}$ ) could result in erosion rates and slopes of depth development that are lower than that of the arc sprayed coatings. The rates of the latter, in turn, are characterized by quite uniform and linear material removal, in present comparison the coating sprayed on steel (AS 1) showing a significantly better performance. In contrast to the previously described coating groups, the curve shapes for both, the warm spray (WS) and the tempered coldsprayed coatings (CS 2) are rather similar to those of the bulk material. Figure 13(b) and (c), on the other hand, show why the specific intervals, chosen in section "Cavitation Erosion Resistance," were used for determining the longterm characteristics. The erosion rates at the beginning of the test period are several times higher than those suggesting a steady state at longer times between 60 and 120 min. For this reason, the rates at short testing times should not be considered for being characteristic for the sprayed materials, in contrast to the ones determined later on.

Figure 14 compares the initial internal microstructures by means of cross sections and the surface damage morphologies by top views after testing times of 100 and 120 min (arc spray) to provide more information failure mechanisms of the optimized coatings. As a reference, results of the bulk material are included for comparison. The basic failure mechanisms of the different coatings can be considered as representative for the respective combination of material class and spray technology. For nearly all coatings, parts of the originally prepared surface are maintained even after the applied long testing procedures.

The cavitation erosion rates of the bulk bronze and those attained by coatings produced by different processes are associated with different microstructures, even for cases that could ensure similar performance. The cast material shows rather large grain sizes with the typical precipitations scaling up to $\kappa_{2}$ and even $\kappa_{1}$ phases being present (Ref 32) in the cross section as well as plastic deformation due to cavitation with material loss most prominently starting near the grain boundaries. Cold and warm-sprayed coatings show smaller grain sizes than the cast material, mainly retaining the initial powder microstructure during the solid-state impact. The cross sections (and separate analyses) could barely reveal any oxides. The failure under cavitation erosion testing barely reveals plastic deformation of the intrinsically hard or work hardened splats. The cavitation damage appears to be mainly associated with inter-particle failure. In case of the annealed cold-sprayed coatings (sprayed with nitrogen at lower parameter sets), at the surface, some larger areas of material detachment due to loosely bonded particles are visible after cavitation testing, while the internal microstructure does not reveal any changes and, thus indicating still well-bonded internal interfaces between spray splats. In contrast, HVOF- and

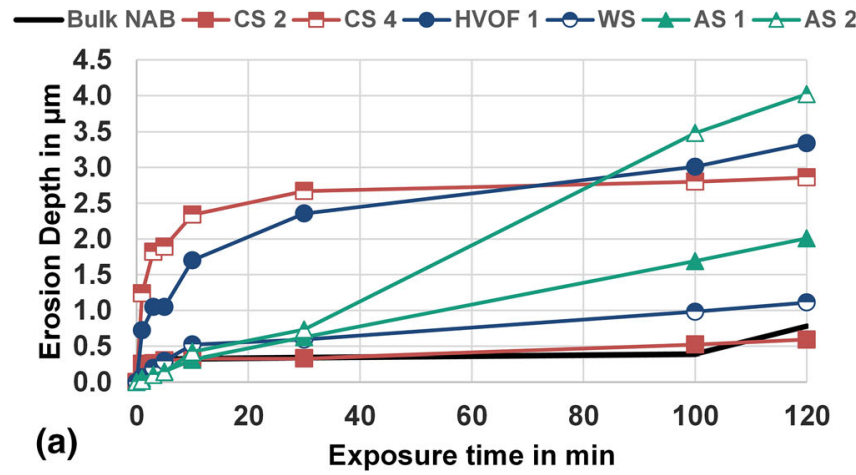

Fig. 13 Comparison of the (a) erosion depth (MDE) and (b) erosion rates over a test duration of 120 minutes of the individually optimized spraying processes for $\mathrm{Ni}-\mathrm{Al}$ bronze coatings. In (c), an enlarged area of the erosion rates for the second half of the test duration is shown. It

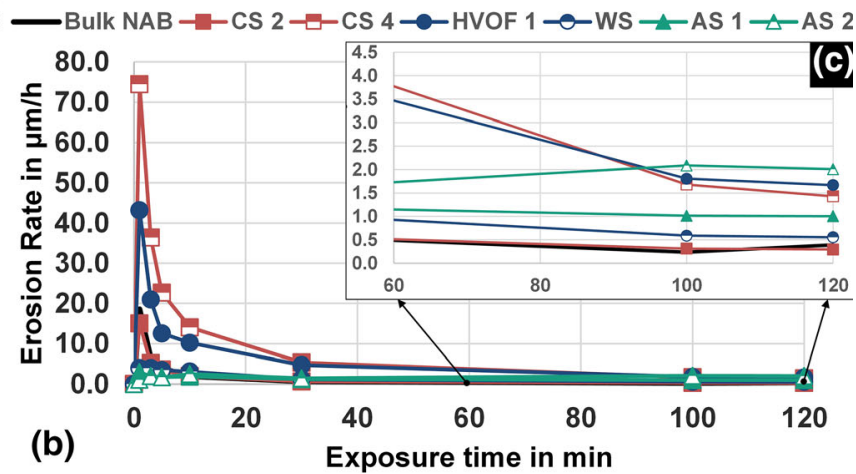

can be seen that the erosion rates for the sprayed coatings are several orders of magnitude higher at the beginning as compared to the end of the test. From about 100 min onward, the rates stabilize 
Fig. 14 (Left) Coatings

microstructures and right)

surface topologies after $120 \mathrm{~min}$

(arc spray) and $100 \mathrm{~min}$,

respectively (other spray methods) of cavitation testing for optimized coatings processed by kinetic and thermal spraying in comparison with those of the cast bulk material

\section{Microstructure}

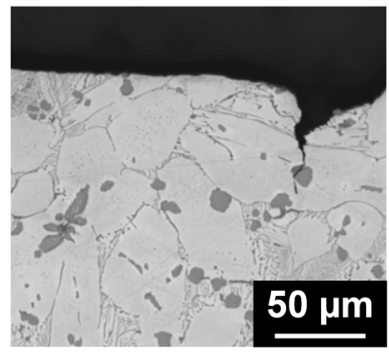

Cold Spray

50 m

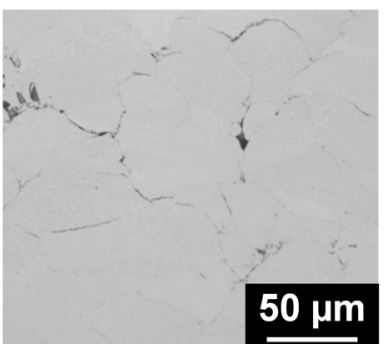

$50 \mu \mathrm{m}$

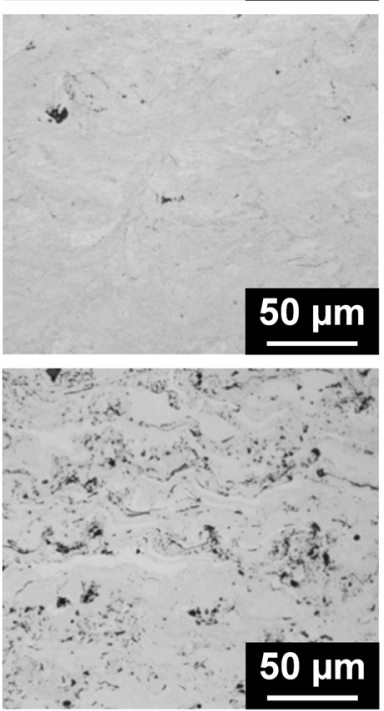

Warm Spray

HVOF Spray

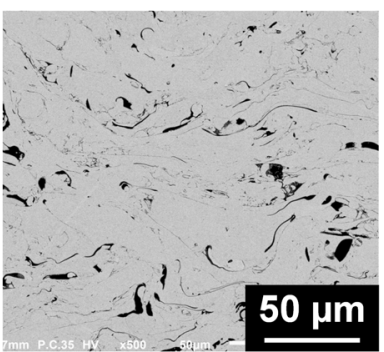

Cold Spray Annealed

\section{After Cavitation}
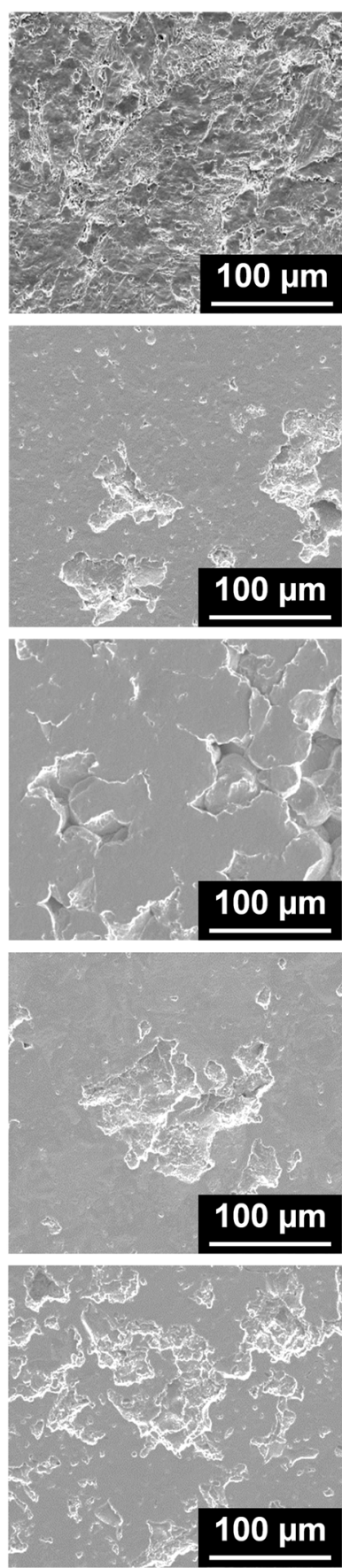

\section{Arc Spray}

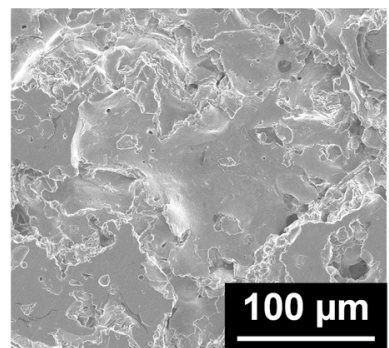


arc-sprayed coatings experience mainly liquid impacts, resulting in visibly higher amounts of oxides (compare also data from separate analyses) and pores, which potentially serve as crack nuclei under externally exposed loads in cavitation testing. Thus, material loss of the thermally sprayed coatings occurs by the removal of complete spray splats. Nevertheless, by minimizing the amount of intersplat oxides, respective cavitation rates could be tuned to reach the same magnitude as optimum warm-sprayed or cold-sprayed coatings, or that of the bulk material.

Table 5 summarizes the coating properties that can be achieved by the previously described optimizations of materials and processes. If no values are specified in some places, no reliable measured data are available for these individual cases.

\section{Discussion}

The results show that hardness alone is not a decisive criterion for assessing cavitation erosion resistance of thermally and kinetically sprayed coatings. Material loss in cavitation involves plastic deformation and failure by local crack nucleation and crack growth. Thus, both, sufficiently strong materials, hindering plastic deformation, and optimum processing conditions, inhibiting possible crack nucleation centers must be considered. Under the cyclic load in the cavitation erosion test, the material is elastically and plastically deformed. Similar to phenomena in fatigue strength tests, cracks form at existing defects, grow under repeated load cycles and finally lead to local fracture and loss of material. Accordingly, erosion rates are high if coatings already contain a large number of defects, such as oxide lamellae or insufficiently bonded internal interfaces, as reflected by measured oxygen contents and porosities. In this case, whole particles are torn out from the surface. This observation applies for the arc sprayed and HVOF-sprayed coatings that show higher amounts of above-mentioned defects. In addition, the local chemical composition of the oxides plays a role, especially in the case of arc sprayed coatings. For MAB, Mn-containing oxides prove to be more ductile and better bonded, while Al-containing oxides tend to cause large-scale detachment under cavitation erosion stress. In contrast, cold-sprayed bronze coatings do

Table 5 Comparison of the coating properties of nickel aluminum bronzes (NAB) as achieved by individual process optimization. The mechanical properties of the cast reference material NAB were taken

from (Ref 32). The coating properties for cold spraying refer to powders previously annealed for $7 \mathrm{~h}$ at $600{ }^{\circ} \mathrm{C}$

\begin{tabular}{|c|c|c|c|c|c|c|c|}
\hline Parameter & $\begin{array}{l}\text { Bulk NAB, } \\
\text { as cast }\end{array}$ & $\begin{array}{l}\text { CS } 2 \text { with } \mathrm{N}_{2} \text {, } \\
\text { tempered coating }\end{array}$ & $\begin{array}{l}\text { CS 4, with } \\
\mathrm{He}\end{array}$ & $\begin{array}{l}\mathrm{HVOF} 1 \text {, with } \mathrm{N}_{2} \\
\text { as cooling gas }\end{array}$ & Warm spray & $\begin{array}{l}\text { AS 1, on } \\
\text { VL-A }\end{array}$ & $\begin{array}{l}\text { AS 2, on } \\
\text { NAB }\end{array}$ \\
\hline \multicolumn{8}{|l|}{ Cavitation erosion resistance } \\
\hline $\begin{array}{l}\text { Erosion depth MDE in } \\
\mu \mathrm{m} \text { (after } 120 \mathrm{~min})\end{array}$ & 0.59 & 0.59 & 2.86 & 3.34 & 1.11 & 2.01 & 4.02 \\
\hline $\begin{array}{l}\text { Erosion rate TER in } \\
\mu \mathrm{m} / \mathrm{h} \text { (after } 120 \mathrm{~min})\end{array}$ & $0.40 \pm 0.14$ & $0.30 \pm 0.01$ & $1.56 \pm 0.18$ & $1.74 \pm 0.10$ & $0.57 \pm 0.02$ & $1.02 \pm 0.02$ & $2.17 \pm 0.17$ \\
\hline \multicolumn{8}{|l|}{ Mechanical properties } \\
\hline $\begin{array}{l}\text { Tensile strength } \mathrm{R}_{\mathrm{m}} \text { in } \\
\mathrm{MPa}\end{array}$ & At least 600 & $363 \pm 22$ & $264 \pm 70$ & 356 & $350 \pm 22$ & $\cdots$ & $\cdots$ \\
\hline $\begin{array}{l}\text { Elongation at break A } \\
\text { in } \%\end{array}$ & At least 13 & $\cdots$ & $\ldots$ & $\cdots$ & $\cdots$ & $\cdots$ & $\cdots$ \\
\hline \multicolumn{8}{|c|}{ Adhesion and functional properties } \\
\hline $\begin{array}{l}\text { Tensile adhesive } \\
\text { strength } \mathrm{R}_{\mathrm{H}} \text { in } \mathrm{MPa}\end{array}$ & $\cdots$ & $28 \pm 9$ & $31 \pm 4$ & 56 & $38 \pm 6$ & $43 \pm 1$ & - \\
\hline $\begin{array}{l}\text { Electrical conductivity } \\
\sigma \text { in } \mathrm{MS} / \mathrm{m}\end{array}$ & $4.79 \pm 0.21$ & $5.35 \pm 0.02$ & $4.85 \pm 0.06$ & 2.5 & $2.97 \pm 0.07$ & $9.27 \pm 0.24$ & $14.71 \pm 0.50$ \\
\hline $\begin{array}{l}\text { Hardness in HV0, } \\
\text { 3/HV1 (for Arc Spray) }\end{array}$ & $240 \pm 10$ & $278 \pm 15$ & $350 \pm 17$ & 400 & $401 \pm 20$ & $167 \pm 18$ & $166 \pm 8$ \\
\hline \multicolumn{8}{|l|}{ Microstructure } \\
\hline $\begin{array}{l}\text { Coating thickness in } \\
\mu \mathrm{m}\end{array}$ & $\cdots$ & 680 & 630 & $\cdots$ & $>400$ & $538 \pm 17$ & $513 \pm 14$ \\
\hline Porosity in \% & $\ldots$ & $1.7 \pm 0.4$ & $0.7 \pm 0.2$ & 0.85 & $0.9 \pm 0.09$ & $3.04 \pm 0.58$ & $4.18 \pm 0.68$ \\
\hline $\begin{array}{l}\text { Oxygen content in } \\
\text { wt. } \%\end{array}$ & $\cdots$ & $\cdots$ & $0.06 \pm 0.01$ & 0.1 & $1.02 \pm 0.07$ & $4.36 \pm 0.60$ & $4.34 \pm 0.12$ \\
\hline
\end{tabular}


not contain oxides as possible failure sites. However, serious efforts are needed to maximize well-bonded internal interface areas, thus decreasing initial crack-area. Correspondingly, optimized spray conditions and coating annealing procedures can reduce weakly bonded interface area to subcritical dimensions. Consequently, respective coatings do not fail at inter-splat boundaries anymore then. Instead, material loss can only occur by deformation and fatigue of parts of the initial spray splats. Therefore, the cavitation resistance of the different coatings scales rather well with their experimentally determined ultimate tensile strengths (UTS). Additionally, the stress states of the coatings could influence cavitation resistance. For the kinetic/solid-state processes (Cold and Warm Spray) and HVOF, the role of residual stresses is of more indirect nature, facilitating partly stress-induced transformation from high-temperature martensite to $\alpha$-phase (Ref 5). Final intrinsic coating stresses are mostly slightly compressive and seem not to play a major role for cavitation resistance. The stress state of HVOF-sprayed coatings is influenced by the oxygen to fuel ratio, possibly or not contributing to a lower cavitation erosion resistance at higher values $(\lambda>$ 0.7) (Ref 5). For arc spraying, on the other hand, a dependence of the final coating quality on the height and course of the residual stress depth profile was found. However, this influence diminishes by optimizing the process gas or the heat transfer, or by changing to a substrate of the same type (Ref 6, 26, 27, 34).

Defects in the coating microstructure do not only affect the mechanical properties but also their electrical conductivity. For the present examples, the cavitation resistance also scales well with the electrical conductivity in cases of cold spraying and HVOF-spraying. Particularly with respect to conductivity, the different influences of oxides, non-bonded interfaces and solute atoms within the material should be distinguished, the two former playing the main role here. It should be noted that the specific electrical conductivity of aluminum bronzes decreases exponentially with increasing aluminum content in the matrix of the material (Ref 32). This means that an increase in specific electrical conductivity in thermal spraying processes with strong oxidation such as arc spraying is not necessarily associated with improved coating quality. Here, better mechanical coating properties under high-end spraying conditions are associated with low levels of oxidation that correspond to lower electrical conductivity by the higher, non-oxidized amounts of $\mathrm{Al}$ in the matrix material. With respect to possible applications, it should be noted here that all of the optimized coatings show sufficiently high adhesive strengths to fulfill required needs.

\section{Summary and Conclusion}

In this work, bronze coatings produced under optimum conditions by different spray techniques, i.e., cold spraying, warm spraying, HVOF spraying and arc spraying are compared with respect to their maximum cavitation erosion resistance.

Depending of the exposure times of the completely or partially molten material to atmospheric oxygen, the qualities of the coatings are compromised by incorporated oxides. Nevertheless, process optimization can significantly improve qualities. Optimum arc sprayed or HVOFsprayed coatings show 16 to 26 times better cavitation erosion resistance than the typical rudder material steel VL-A. However, the coatings still show about four or three times higher erosion rates than coatings produced by warm spraying, which largely avoids oxidation: respective coatings successfully reach properties that are comparable to bulk cast nickel aluminum bronze. Cold spray processing of hard Ni-Al bronze is challenging, but can also successfully yield coating qualities similar to that of bulk material, if soft annealed powder are used and coating heat treatments are applied. Interestingly, cold-sprayed coatings on basis of Mn-containing bronzes can achieve cavitation resistances similar to cast propeller bronze, without any heat treatments, however, using cost-intensive helium as process gas. Using softer bronzes, nitrogen is sufficient to facilitate high amounts of bonded interfaces, but these materials have shown to be intrinsically too soft to provide the desired cavitation erosion resistance.

In conclusion, the comparison thus gives guidelines for process selection with respect to applications. For improvement of steel VL-A part life times by an order of magnitude, HVOF and arc spraying prove to be a good compromise between good coating properties and robust economic operation for the maritime industry. For highest quality coatings that require cavitation erosion resistance similar to the specified bulk material, cold and warm spraying are the methods of choice, although at higher costs.

Acknowledgments The authors would like to thank all co-workers involved in the study, namely listed in alphabetical order: R. Arndt, R. Banaschik, T. Breckwoldt, M. Henke, A. Herhaus, C.-P. Homburg, D. Krüger, R. Lange, H. Katanoda, N. Németh, A. Novikov, C. Pust, B. Ripsch, A. Schober, C. Schulze, M. Schulze, K. Utwich and S. Wachtmann. The research projects (No. 17135 BG and 18449 BG) of the Research Association for Shipbuilding and Marine Technology e.V. (FSM), Steinhöft 11, 20459 Hamburg have been funded by the AiF within the program for sponsorship by Industrial Joint Research (IGF) of the German Federal Ministry of Economic Affairs and Energy based on an enactment of the German parliament. This support is gratefully acknowledged. 
Funding Open Access funding enabled and organized by Projekt DEAL.

Open Access This article is licensed under a Creative Commons Attribution 4.0 International License, which permits use, sharing, adaptation, distribution and reproduction in any medium or format, as long as you give appropriate credit to the original author(s) and the source, provide a link to the Creative Commons licence, and indicate if changes were made. The images or other third party material in this article are included in the article's Creative Commons licence, unless indicated otherwise in a credit line to the material. If material is not included in the article's Creative Commons licence and your intended use is not permitted by statutory regulation or exceeds the permitted use, you will need to obtain permission directly from the copyright holder. To view a copy of this licence, visit http://creativecommons. org/licenses/by/4.0/.

\section{References}

1. J. Carlton, Rudder-Propeller-Hull Interaction: The Results of Some Recent Research, In-Service Problems and Their Solutions, in Proceedings of the 1st International Symposium on Marine Propulsors-Smp'09: June 22-24, 2009 (Trondheim, Norway), ed. by K. Koushan, S. Steen, 2009, p. 262-269.

2. ASTM, Test Method For Cavitation Erosion Using Vibratory Apparatus, G32, ASTM, ASTM International, West Conshohocken, PA, USA, 2016

3. Naval Surface Treatment Center, Rudder Coating Failures on Navy Ships, 2003. http://slideplayer.com/slide/2373629/.

4. J. Carlton, Marine Propellers and Propulsion, 2nd ed. Butterworth-Heinemann, Oxford, 2007.

5. S. Krebs, Thermal and Kinetic Spraying of Bronze Materials for Cavitation Protection in Marine Enviroments: Thermisches und kinetisches Spritzen von Bronzematerialien zum Kavitationsschutz im maritimen Umfeld, Doctoral Thesis, Helmut-SchmidtUniversity, 2016.

6. M. Hauer, R. Banaschik, W. Kroemmer, and K.-M. Henkel, Variation of Heat Input and Its Influence on Residual Stresses and Coating Properties in Arc Spraying with Different Gas Mixtures, J. Therm. Spray Technol., 2019, 28(1-2), p 40-52.

7. S. Krebs, S. Kuroda, H. Katanoda, F. Gaertner, T. Klassen, H. Araki, and S. Frede, Warm Spraying of High-Strength Ni-AlBronze: Cavitation Characteristics and Property Prediction, $J$. Therm. Spray Technol., 2017, 26(1-2), p 265-277.

8. L. Pawłowski, The Science and Engineering of Thermal Spray Coatings, 2nd ed. Wiley, Hoboken, 2008.

9. J.R. Davis, Handbook of Thermal Spray Technology, ASM International, Materials Park, 2004.

10. T. Klassen, F. Gärtner, and H. Assadi, Process Science of Cold Spray: Chapter 2, High Pressure Cold Spray, ed. by C.M. Kay, J. Karthikeyan (ASM International, Materials Park, 2016), pp. 1765 .

11. H. Assadi, H. Kreye, F. Gärtner, and T. Klassen, Cold SprayingA Materials Perspective, Acta Mater., 2016, 116, p 382-407.

12. H.-A. Mathesius and W. Krömmer, Practice of Thermal Spraying: Guidance for Technical Personnel, 2nd ed. DVS Media, Düsseldorf, 2014.

13. F.-W. Bach Ed., Modern Coating Technologies: ModerneBeschichtungsverfahren, Wiley-VCH, Weinheim, 2005 ((in ger))

14. T. Stoltenhoff, H. Kreye, and H.J. Richter, An Analysis of the Cold Spray Process and Its Coatings, J. Therm. Spray Technol., 2002, 11(4), p 542-550.
15. H. Assadi, F. Gärtner, and T. Klassen, Modeling and Simulation of Cold Spray: Chapter 3, High Pressure Cold Spray, ed. by C.M. Kay, J. Karthikeyan (ASM International, Materials Park, 2016), pp. 67-98.

16. H. Kreye, F. Gärtner, A. Kirsten, and R. Schwetzke, High Velocity Oxy-Fuel Flame Spray: State of the Art, Prospects and Alternatives, in Proc. Hvof Spraying: November 16-17, 2000, Erding, Germany, ed. by P. Heinrich (Gemeinschaft Thermisches Spritzen e.V., 2000), pp. 5-16.

17. B. Wielage, A. Wank, H. Pokhmurska, T. Grund, C. Rupprecht, G. Reisel, and E. Friesen, Development and Trends in Hvof Spraying Technology, Surf. Coat. Technol., 2006, 201(5), p 20322037.

18. W. Krömmer and P. Heinrich, Influence of Gases in Thermal Spraying, in Proc. Hvof Spraying: November 5-6, 2009, Erding, Germany; focal point: cold spraying, equipment + applications, ed. By C. Penszior (Gemeinschaft Thermisches Spritzen e.V., 2009), pp. 117-121.

19. K. Dobler, H. Kreye, and R. Schwetzke, Oxidation of Stainless Steel in the High Velocity Oxy-Fuel Process, J. Therm. Spray Technol., 2000, 9(3), p 407-413.

20. H.J. Richter and G. May, Fluid Mechanic and Thermal Aspects of High Velocity Spraying, in Proc. Hvof Spraying: November 16-17, 2000, Erding, Germany, ed. By P. Heinrich (Gemeinschaft Thermisches Spritzen e.V., 2000), pp. 19-28.

21. J.-H. Kim and M.-H. Lee, A Study on Cavitation Erosion and Corrosion Behavior of Al- $\mathrm{Zn}-, \mathrm{Cu}-$, and Fe-Based Coatings Prepared by Arc Spraying, J. Therm. Spray Technol., 2010, 19(6), p 1224-1230.

22. F. Lang and W. Krömmer, Economic and Ecological Benefits of Using Gas Mixtures for Arc Spraying, in Proc. Hvof Spraying October 29-30, 2015, Erding, Germany, ed. by W. Krömmer (Gemeinschaft Thermisches Spritzen e.V., 2015), pp. 79-88.

23. DIN, Thermal Spraying-Terminology, Classification, German Version En Iso 14917:2017-08, DIN (Beuth Verlag, Berlin, 2017).

24. GTV Verschleißschutz GmbH, Krebs Korrosionsschutz GmbH Rostock, EEW SPC GmbH, Thermal Sprayed Auminium: a Brand-New Robot-Based Technological Coating Concept, 2017. https://www.youtube.com/watch?v=O5v73kPugm0.

25. A. Barth, Application Areas of Arc Spraying: Presentation Within the Seminar. Modern Coating Technologies, November 5, 2014 (in ger).

26. M. Hauer, K.M. Henkel, S. Krebs, and W. Kroemmer, Study of Traverse Speed Effects on Residual Stress State and Cavitation Erosion Behavior of Arc-Sprayed Aluminum Bronze Coatings, $J$. Therm. Spray Technol., 2017, 26(1-2), p 217-228.

27. M. Hauer, K.M. Henkel, S. Krebs, and W. Kroemmer, Alternative Gas Mixtures in Arc Spraying: A Chance to Improve Coating Properties and Residual Stress States, J. Therm. Spray Technol., 2018, 27(1-2), p 106-118.

28. G. Jandin, H. Liao, Z.Q. Feng, and C. Coddet, Correlations Between Operating Conditions, Microstructure and Mechanical Properties of Twin Wire Arc Sprayed Steel Coatings, Mater. Sci. Eng. A, 2003, 349(1-2), p 298-305.

29. C. Rupprecht, Efficient Solutions for Wire Arc Spraying: Presentation at the International Thermal Spray Conference and Exposition 2017, June 8, 2017.

30. S. Kuroda, M. Watanabe, K. Kim, and H. Katanoda, Current Status and Future Prospects of Warm Spray Technology, $J$. Therm. Spray Technol., 2011, 20(4), p 653-676.

31. H. Katanoda, B. Sun, N. Ohno, H. Fukanuma, S. Kuroda, S. Watanabe, and O. Ohashi, Design and Development of HighPressure Warm Spray Gun, Innovative Coating Solutions For the Global Economy: International Thermal Spray Conference \& 
Exposition (ITSC 2013); Busan, Republic of Korea, 13-15 May 2013, ed. by R. Lima (Curran, Red Hook, 2014), pp. 196-199.

32. H.J. Meigh, Cast and Wrought Aluminium Bronzes: Properties, Processes and Structure, Maney Publishing, Leeds, 2008.

33. S. Krebs, F. Gärtner, and T. Klassen, Cold Spraying of Cu-AlBronze For Cavitation Protection in Marine Environments, $J$. Therm. Spray Technol., 2014, 24(1), p 126-135.

34. M. Hauer, S. Krebs, W. Kroemmer, and K.-M. Henkel, Correlation of Residual Stresses and Coating Properties in Arc-Sprayed Coatings on Different Substrates For Maritime Applications, $J$. Therm. Spray Technol., 2020, 29(6), p 1289-1299.

35. F. Gärtner, T. Stoltenhoff, J. Voyer, H. Kreye, S. Riekehr, and M. Koçak, Mechanical Properties of Cold-Sprayed and Thermally Sprayed Copper Coatings, Surf. Coat. Technol., 2006, 200(24), p 6770-6782.

36. DIN, Thermal Spraying-Determination of Tensile Adhesive Strength, German Version En Iso 14916:2017-03, DIN (Beuth Verlag, Berlin, 2017).

37. ASTM, Test Method For Determining Electrical Conductivity Using the Electromagnetic (Eddy-Current) Method, E1004 (ASTM, ASTM International, West Conshohocken, 2017).
38. DIN, Metallic Materials_-Vickers Hardness Test-Part 1: Test Method, German Version En Iso 6507-1:2018-01, DIN (Beuth Verlag, Berlin, 2018).

39. ASTM, Test Methods For Determining Area Percentage Porosity in Thermal Sprayed Coatings, E2109 (ASTM, ASTM International, West Conshohocken, PA, 2014).

40. H. Assadi, I. Irkhin, H. Gutzmann, F. Gärtner, M. Schulze, M. Villa Vidaller, and T. Klassen, Determination of Plastic Constitutive Properties of Microparticles Through Single Particle Compression, Adv. Powder Technol., 2015, 26(6), p 1544-1554.

41. B. Vyas and C.M. Preece, Cavitation Erosion of Face Centered Cubic Metals, MTA, 1977, 8(6), p 915-923.

42. R.H. Richmann and W.P. McNaughton, A Metallurgical Approach to Improved Cavitation-Erosion Resistance, J. Mater. Eng. Perform., 1997, 6(5), p 633-641.

Publisher's Note Springer Nature remains neutral with regard to jurisdictional claims in published maps and institutional affiliations. 